\title{
Agenda Building in Health Communication: How the CDC is Using Traditional and Social Media Tactics in Public Relations
}

Kristen Wishon

West Virginia University

Follow this and additional works at: https://researchrepository.wvu.edu/etd

\section{Recommended Citation}

Wishon, Kristen, "Agenda Building in Health Communication: How the CDC is Using Traditional and Social Media Tactics in Public Relations" (2012). Graduate Theses, Dissertations, and Problem Reports. 3354. https://researchrepository.wvu.edu/etd/3354

This Thesis is protected by copyright and/or related rights. It has been brought to you by the The Research Repository @ WVU with permission from the rights-holder(s). You are free to use this Thesis in any way that is permitted by the copyright and related rights legislation that applies to your use. For other uses you must obtain permission from the rights-holder(s) directly, unless additional rights are indicated by a Creative Commons license in the record and/ or on the work itself. This Thesis has been accepted for inclusion in WVU Graduate Theses, Dissertations, and Problem Reports collection by an authorized administrator of The Research Repository @ WVU. For more information, please contact researchrepository@mail.wvu.edu. 
Agenda Building in Health Communication: How the CDC is Using Traditional and Social Media Tactics in Public Relations

\title{
Kristen Wishon
}

\author{
Thesis submitted to the \\ P.I. Reed School of Journalism \\ at West Virginia University \\ in partial fulfillment of the requirements \\ for the degree of
}

\author{
Master of Science \\ in \\ Journalism
}
Diana Martinelli, Ph.D., Chair
Rita Colistra, Ph.D.
Dana Coester, M.A.
Stephanie Bock, M.S.J.

School of Journalism

Morgantown, West Virginia

2012

Keywords: public relations, social media, health communication, agenda setting, agenda building, Centers for Disease Control and Prevention, CDC

Copyright 2012 Kristen Wishon 


\begin{abstract}
Agenda Building in Health Communication: How the CDC is Using Traditional and Social Media Tactics in Public Relations
\end{abstract}

\begin{abstract}
Kristen Wishon
Emerging Internet technologies, such as social networking websites and blogs, are influencing how public relations practitioners choose to disseminate health content to their constituents. Using the agenda-building theory as a guide, this exploratory study used both qualitative and quantitative methods to examine the Centers for Disease Control and Prevention's (CDC) social media and traditional media health messages, as well as to explore if these messages had any agenda-building effect on mainstream media placement (i.e., the Associated Press).

Personal interviews with CDC health communication specialists and three content analyses were conducted. Two significant correlations were found between the health topics in the CDC's press releases and the topics in AP articles, and the topics of the CDC's Twitter account, @CDCgov, and the topics in AP. These findings suggest the importance of using both traditional and social media in media relations work and using a strategic, integrated approach to disseminate the content of health organizations.
\end{abstract}




\section{Acknowledgements}

I have learned more throughout the duration of my thesis research than in any other time in my life. I owe a huge thanks to several people for imparting the importance research in real world application, as well as perseverance, humility, and most importantly and simply, patience.

I would like to thank my committee chair, Dr. Diana Martinelli, for her support and guidance throughout this study. Dr. Martinelli has guided me not only throughout my graduate career, but also during my undergraduate experience, serving as my professor, advisor, and mentor for the past 4 years. Your always professional and expert advice, heartening encouragement, and constant correspondence contributed to this study's success. Thank you for growing a love for research and public relations in me.

It has also been a privilege to have three remarkable committee members and skillful professionals - Dr. Rita Colistra, Dana Coester, and Stephanie Bock aid in the development and refinement of this study. You each have irreplaceable professional knowledge and character that refined the many levels of this study. I thank you each for your time and support.

l'd like to express huge thanks to the Centers for Disease Control and Prevention (CDC) interview participants. Thank you for your kindness, openness, and expertise. Your assistance and cooperation have contributed to this study's findings and to communications research today.

I would also like to thank my boyfriend, Jonny Blevins, who was abroad in China throughout the duration of this research. Thank you for your eternal support, encouragement, and humor. Like you said, "Luck is when preparation meets opportunity!"

To all of my great friends, especially those out of state, thank you for putting up with weeks of missed phone calls. Friends are born, not made. Special thanks to Cat Lovell, my wonderful second coder, and Deepa Fadnis.

The acknowledgements would not be complete without expressing my gratefulness to my family. Life has certainly put unnerving obstacles in our path, yet we always have a way of laughing through it and supporting each other.

Thank you for making me the person I am today. 


\section{Table of Contents}

$\begin{array}{ll}\text { I. Introduction } & 1\end{array}$

II. Literature Review 4

$\begin{array}{ll}\text { Health Communication } & 4\end{array}$

$\begin{array}{ll}\text { Social Media and Health Content } & 6\end{array}$

$\begin{array}{lr}\text { Mass Communication and Health } & 13\end{array}$

$\begin{array}{lr}\text { Agenda Setting and Agenda Building } & 16\end{array}$

The CDC, Public Health, and the Internet 20

III. Research Questions 23

IV. Methodology 25

$\begin{array}{ll}\text { About the CDC } & 26\end{array}$

$\begin{array}{ll}\text { Qualitative Approach } & 27\end{array}$

$\begin{array}{ll}\text { Quantitative Approach } & 30\end{array}$

$\begin{array}{ll}\text { Data Analysis } & 34\end{array}$

$\begin{array}{ll}\text { V. Results } & 37\end{array}$

$\begin{array}{ll}\text { Interview Results } & 37\end{array}$

Content Analysis Results $\quad 45$

$\begin{array}{ll}\text { VI. Discussion } & 64\end{array}$

$\begin{array}{ll}\text { VII. Conclusion } & 70\end{array}$

$\begin{array}{ll}\text { Limitations } & 70\end{array}$ 
Future Research

$\begin{array}{ll}\text { Implications } & 72\end{array}$

$\begin{array}{ll}\text { VIII. References } & 74\end{array}$

$\begin{array}{ll}\text { IX. Appendices } & 81\end{array}$

Appendix A: Interview Guide $\quad 81$

Appendix B: Email Correspondence with Interviewees 83

Appendix C: Phone Interview Transcriptions 88

Appendix D: Coding Sheets \& Instructions 102

$\begin{array}{ll}\text { Appendix E: Codebook } & 110\end{array}$

Appendix F: CDC Organizational Chart 114 


\section{Introduction}

Public relations practitioners often serve as the frontline disseminators of information in public health. These practitioners not only distribute pertinent information about disease outbreaks and epidemics, but they also update the public on health prevention, best practices, and health resources (Lariscy, Amador, Ickowitz, Primm, \& Taylor, 2010). Yet, the way in which practitioners disseminate health information has changed as the social context of the Internet has emerged as a powerful tool for education and outreach in the health field. The general health consumer has begun to rely on websites, online communities, social networking, and blogs to gather health information. With 65 percent of all online adults using social networking websites, these innovations influence the practice of public relations and how campaigns and key messages are disseminated (Madden \& Zickuhr, 2011).

Public relations practitioners at several health organizations, such as the Centers for Disease Control and Prevention (CDC), are beginning to use social networking and blogging tactics, in conjunction with traditional tactics, to communicate with their publics (CDC, 2010a). According to the CDC, social media tools are powerful channels "to reach target audiences with strategic, effective and user-centric health interventions" (CDC, 2011b, para. 1). Such health-based social networking websites and blogs are being used to affect learning experiences of caregivers, clinicians, and patients, as well as to promote social support and collaboration (Buis, 2009, p. 704). In particular, the $\mathrm{CDC}$ has engaged in these integrated strategies, covering events such as the "H1N1 flu event, the Salmonella Typhimurium outbreak associated with peanut butter and peanut- 
containing products, as well as annual seasonal influenza vaccination campaigns" (Centers for Disease Control and Prevention, 2009, para. 1).

In 2010, searching for health information was the third most popular online activity for adults on the Internet (Zickuhr, 2010, para. 7). The younger generations are more likely to engage on social networking sites (2010). However, Baby Boomers and seniors 65 and older have both seen rapid growth in adoption rates of social networking (Department of Health, 2010b). The use of these social media tools in the health communication field by practitioners allows the dissemination timely information, engagement with distinct audience networks, and public engagement to diverse communities (Centers for Disease Control and Prevention, 2010a, para. 1). According to Sharp, it's not only the patients that are turning to the Internet and social media (2010). In 2010, hospitals and academic medical centers accounted for more than 300 YouTube channels and 500 Twitter accounts (2010).

Avery, Lariscy, Amador, Ickowitz, Primm, and Taylor (2010) explain the phenomena best: "Social media, like the very basis of public relations itself, build relationships" (p. 337). By combining social and traditional media tactics with government information, organizations such as the CDC can reach a large audience at once. However, little empirical research has been conducted on the content of these social media tools in a health context or their effects on the mainstream news agenda. In addition, the effect these new public relations tactics have on garnering traditional media placement has not yet been studied. 
Therefore, the purpose of this study is to compare the health content (agendas) of the CDC's social media and traditional tactics, while thus comparing that content to mainstream media health content to discover if there is an agenda-building association. 


\section{Literature Review}

Health communication is the study and application of the generation, creation, and dissemination of health-related information, health-related interactions among individual social actors, and their effects on different publics including individuals, community groups, and institutions (Viswanath, 2008, para. 1). Health communication draws from multiple fields, including mass communication, journalism, communication studies, and public health (Viswanath, 2008, para. 1). Medical and health blogs, social networking, and the Internet have emerged as additional connections between health professionals, organizations, and the public (Lagu, 2007). These resources have become a source of research in journalism and mass communication. It's important to discuss the role traditional mass communication and journalism play in health communication. However, it's also valuable to define the roles social media tools, their authors and contributors, and the fields these tools influence, including health communication, traditional journalism, public relations, and public health.

\section{Health Communication}

K. Viswanath (2008) defines five levels of analysis for health communication: individual, interpersonal, social network, organizational, and mass or societal levels. The organizational level of health communication has been studied within the healthcare system and media practices (Viswanath, 2008, para. 7). The societal level of health communication focuses on "large-scale social changes and the role of communication with such changes" (2008, para. 8). Both the organizational and mass/societal levels of health communication may be impacted by the use of social media, in addition to traditional media. Media influence in health is also an important 
aspect of health communication and can occur through exposure to messages through routine media use and strategic use of media (Viswanath, 2008). Strategic use of media refers to consumption of public relations, advertising, media relations, and strategic communications messages. Routine media use refers to the consumption of traditional media, such as television, radio, and print.

\section{E-Health.}

An important aspect of health communication is e-health. According to Polack and Avtgis (2011), e-health refers to the use of the Internet, email, and other mediated technologies in the healthcare realm. The use of the Internet in this health communication aspect has broadened the scope of interpersonal interaction by changing the limits of geography (Viswanath, 2008, para. 26). Eysenbach (2001) attributes the emergence of the term e-health to industry leaders and marketing representatives in order to convey the promises, principles, and excitement around ecommerce (electronic commerce) to the health arena. Eysenbach argues that e-health increases the quality of care, enables a greater exchange of health information, increases health equity and decreases health disparities, and empowers health consumers and patients (2001).

E-health consumers have been coined e-patients. E-patients are "patients who utilize technology for social support and social networking resources that are specific to their disease or medical situation" (Polack \& Avtgis, 2011, p. 250). According to statistics from Nielsen and the Pew Research Center, 55 percent of Americans use the Internet every day and spend 60 hours a month online (Smith, 2010, para. 2). Approximately 61 percent of adults seek online information pertaining to healing (Polack 
\& Avtgis, 2011). The Pew Research Center estimates that 92 percent of Americans who seek health information online find this information useful (Fox \& Rainie, 2000, para. 2). The information-seeking behavior that is displayed by a large majority of Americans in this Web 2.0 generation has resulted "in hundreds of sites being created for disease specific" topics (Polack \& Avtgis, 2011, p. 250).

\section{Social Media and Health Content}

In addition to serving a social and informative role in health communication, public relations professionals are using social media websites and tools in a strategic way. The strategic use of social networking and blogs, in conjunction with traditional public relations tactics, has become a common strategy used by public relations practitioners in health campaigns (Viswanath, 2008, para. 42). Governmental organizations such as the Centers for Disease Control and Prevention (CDC) maintain multiple blogs and social networking forums, such as Facebook and Twitter, that serve as promotional and educational outlets for the public to access credible health information.

According to Sweetser and Lariscy (2008), "social media" is defined as being "centered around the concept of a read-write Web, where the online audience moves beyond passive viewing of Web content to actually contributing to the content" (p. 179). Social media can include social networking websites, blogs, wikis, RSS feeds, podcasts, and webcasts. All of these tools are generally associated with Web 2.0, which involves user participation, information sharing, and collaboration (Briggs, 2010). Specifically, social networking websites have grown in usage substantially over the past few years. Popular social networking websites include Facebook, Twitter, and Linkedln. 
A 2011 survey by the Pew Internet \& American Life Project found that 65 percent of adults use a social networking website such as Facebook, which is up from 61 percent in 2010 (Madden \& Zickhur, 2011, para. 1). However, adult involvement in social networking health websites varies. In 2009, 29 percent of adults used social networking websites for health management, while 12 percent used Twitter to share or receive health updates (Pew Research Center, 2009). In addition, a 2011 survey found additional levels of involvement: $15 \%$ of users have pursued health information; $14 \%$ have raised money for or drawn attention to a health-related issue or cause; and $11 \%$ have posted comments, queries, or information about health or medical matters (Fox, 2011, para. 2).

According to Avery et al. (2010), social media tools offer large promise for health communication because the topic is largely desired and "people tend to want immediate information that is immediately available online when faced" with health concerns ( $p$. 337). A study by Chou, Hunt, Beckjord, Moser, and Hesse (2009, para. 17) found that social networking websites were the form of social media used most by their sample (23\%), which was drawn from a national survey, followed by blogging $(7 \%)$, and online support groups (5\%). In addition, it was found that use of social networking and blogs for health information was not associated with health status (2009, para. 18). Most importantly, among these Internet users, social media tools were popular in use regardless of education, race/ethnicity, or health care access (Chou et al., 2009, para. 18). This suggests significant support for the continued use of social media in health communication. 
Unfortunately, little critical analysis has been conducted on social networking sites in health communication specifically. Nevertheless, the impact of social media is undeniable on the health world. Current health promotion and program efforts are including facets of many social media tactics. The American Medical Association (AMA) has released a best practices document called "Professionalism in the Use of Social Media" for physicians. Other programs have integrated social media into "efforts such as smoking cessation and dietary interventions" (Chou et al., 2009, para. 2). However, a study by Waters, Burnett, Lamm, and Lucas (2009) suggested that nonprofit organizations in their sample, many of which were health-related, were only utilizing social networking websites for advertising purposes.

The impact of using social networking sites on public relations strategies, such as Facebook and Twitter, has been studied. A study by Edman (2010) analyzed 47 corporations Twitter homepages and tweets during a one-week sampling period. The study found that 63.3 percent of the corporate tweets demonstrated a desire to build and maintain relationships with users (p. 92). It was also found that many corporations use Twitter as a form of customer service, product promotion, news announcements, and engagement (2010, p. 95). Other students have looked at the impact of Twitter from a corporate social responsibility (CSR) and public relations perspective. A study by Etter, Plotkowiak, \& Stanoevska-Slabeva (2011) analyzed 165 corporate Twitter accounts and CSR activity. It was found that the analyzed companies varied substantially in their intensity and degree of CSR communication but concluded that Twitter has potential in promoting CSR efforts (2011). 
Polack and Avtgis (2011) use the social networking site, Patientslikeme.com, as an example of an emerging support and social service for e-patients.

Patientslikeme.com is a social network that offers peer-to-peer advice on daily living and treatments for a variety of diseases (Fox, 2009). It was found that two-thirds of the HIV community members on the website felt more knowledgeable about the risks and benefits of treatments due to interactions with other users on the website (Fox, 2009, para. 25). Another example of social networking emerging in the health context is Hello Health, a Brooklyn-based primary care center that largely uses social media to communicate with patients (Hawn, 2009). The care center profits from patients' monthly and per visit office fees, in addition to selling customized versions of its communication platform to corporate clients (2009).

Despite the uses and benefits of social media in health, there are also indirect negative health impacts from using these tools (Chou et al, 2009). First, the open exchange of content and information on the Internet causes the likelihood that some erroneous or noncredible health information will be exchanged (Chou et al., 2009, para. 3). There is also a portion of the population without access to the Internet. This may prevent them from gaining important health information that individuals with Internet access are receiving (Chou et al., 2009). Lastly, there are legal ramifications for these social networking platforms when used for health purposes (Hawn, 2009). The lines of malpractice, privacy, and standards of care tend to blur when health information is exchanged online (Hawn, 2009).

Web logs, commonly called blogs, are defined as "frequently modified Web pages in which dated text entries are archived in reverse chronological order" (Briggs, 
2010). Specifically, a health or medical blog can be defined as a blog whose primary objective is to provide information related to health and medical issues (Buis \& Carpenter, 2009). Because healthcare consumers and patients often use the Internet to retrieve medical information, a substantial health care blogging community has emerged.

Data show that during 2010, there was a decline in the usage of blogs in teens and the Millennial generation (Zickuhr, 2010, para. 8). According to the Pew Research Center (2010), "blogging's popularity increased among most older generations, and as a result the rate of blogging for all online adults rose slightly overall from 11 percent in late 2008 to 14 percent in 2010 ." In addition, both genders are equally represented in the blogging community (Buis \& Carpenter, 2009, p. 704).

Recently, the CDC's NIOSH Science Blog published a study that was featured in the American Journal of Industrial Medicine. This study used "an online survey accessed on the NIOSH Science Blog to evaluate the blog's effectiveness" and found that the demographics of blog readers fell closely in line with the Pew Research Center statistics (Sublet, Spring \& Howard, 2011, p. 2). The blog readers were 40 years of age or older and were evenly split between male and female (Sublet, et al., 2011, para. 3). The study also found that blog readers were most often looking for $\mathrm{NIOSH}$ health information, safety tips, educational information, research information, explanation of research, and opportunity to contact $\mathrm{NIOSH}$ (2011, para. 3).

Past research has also explored the credibility, professionalism, and characteristics of health bloggers. A study by Miller and Pole (2010) identified a total of 951 health blogs from June to July 2007 and April to May 2008. This study found that 
about half of the health bloggers worked in health professions. However, the other half of these health bloggers were often also in the medical community as health consultants, counselors, emergency responders, researchers, medical journalists, or therapists. The average age of these health bloggers was 35.8 years and the majority of these bloggers were highly educated, with 67 percent having a master's degree or doctorate (Miller \& Pole, 2010).

Similarly, Lagu, Kaufman, Asch, and Armstrong (2007) conducted a snowball sample of medical blogs using Google search terms. The study sample found a total of 271 health or medical blogs written by a doctor or nurse (2007). Their sample indicated that physicians, including interns and residents, authored 76 percent of the sampled blogs. The study also found that the content of these medical blogs derive their credibility from their relationship to health professions and reflect these fields (Lagu et al., 2007). Conversely, a study on health bloggers and blog content by Buis and Carpenter (2009) found that 32 percent of the bloggers in their sample did not identify their professional credentials. The study also found that the credentialed authors posted more topic-specific and more frequent posts than the noncredentialed bloggers (Buis \& Carpenter, 2009). This finding indicates that health professionals are posting about their topics of specialization. These studies provided similar findings about the characteristics and professional background on health bloggers. It seems the majority of health bloggers are educated and their age range falls in line with the Pew Research Center's age of bloggers and blog readers.

Reader perceptions of these blogs have also been studied. Johnson and Kaye (2004) investigated perceived blog credibility by blog readers and found that the 
majority of participants found blogs to be moderately to very credible. Similarly, a study by Buis and Carpenter found that users in their sample found blogs to be "more credible than traditional forms of offline media" (Buis \& Carpenter, 2009, p. 704). However, the sample only included blog readers, which may contain bias (Buis \& Carpenter, 2009). Buis and Carpenter attribute this to the theory of homophily, which indicates that humans are attracted to sources like themselves (2009). They suggest that blog readers may rate their own perceived credibility higher than individuals who do not regularly read blogs.

Several studies have been conducted on the content of health blogs. Through these studies, the roles and impact of health blogs have been discovered. Most often, health blogs have the potential to provide interactive support and engagement for patients, health care workers, and caregivers (Miller \& Pole, 2010). These blogs generate real-time discussions about health news and policy, and at the same time "extend social and political mobilization movements" (Miller \& Pole, 2010, p. 1514). This mobilization allows for transparency of content in promoting health topics, especially if those topics suggest behavior change (2010). These health blogs also offer the opportunity for health care providers and researchers to collaborate and consult on topics, as well as to chronicle the personal experiences and interactions of health professionals (Miller \& Pole, 2010).

In contrast, Buis and Carpenter (2009) found that the majority of the blog posts in their sample focused on responding to external media. However, their sample size was significantly smaller (72 blogs) than Miller and Pole's study (951 blogs). Buis and Carpenter did find about half of the posts were devoted to topic-specific issues while the 
other half were devoted to general medical issues (2009). These studies suggest that the content of health and medical blogs most often address particular issues that are correlated with the blog author's professional credentials. As previously noted, many of these blogs provide readers with a network of support and education regarding conditions. However, the two studies differ in referring to the external media. Miller and Pole's study did not mention any incidence of responding to external media topics. Buis and Carpenter found a significant number of posts that responded to media.

\section{Mass Communication and Health}

In health communication, media influence is an important factor in promoting health messages, news, and interactions. Traditionally, media serve as intermediaries for translating health information into forms easily understood by the public (Wallington et al., 2010). These health communication intermediaries can include facets of advertising, public relations, entertainment, television, and news. In addition, the news media influence the public, but also influence scientists, physicians, and health care policy (Wallington et al., 2010).

In the health field, there are four functions of routine media use: informational, instrumental, social control, and communal (Viswanath, 2008, para. 32). All four functions can apply to the use of medical and health blogs and social networking websites. First, the informational function of media refers to exposing an audience to developments in health care, drugs, risks, and threats (2008, para. 32). Next, the instrumental function focuses on providing information to an audience that will facilitate an action (2008, para. 33). The social control function focuses on defining what is acceptable and is used in health promotion (2008, para. 34). Finally, the communal 
function occurs when the media provide social support and connect people to social institutions. These functions can occur singularly or concurrently (Viswanath, 2008, para. 35).

Because health topics tend to be more complex, reporters often rely heavily on sources of expertise and public relations efforts (Cho, 2006). Public relations practitioners serve as facilitators between the media and their own organizations. Past research has shown that more than 80 percent of the wire stories on health used sources such as official proceedings, press releases, and press conferences (Cho, 2006). Although research on reporter perceptions of public relations practitioners has indicated low thoughts on PR credibility and trust, there is no denying the influence PR holds on news topics (Cho, 2006).

Despite the guarded relationship between journalists and public relations practitioners, the importance of their relationship is represented in the field of media relations. Media relations involves building a positive relationship with media members, as well as gaining knowledge on how to approach journalists and what stories certain publications are likely to run (Austin \& Pinkleton, 2006). Waters, Tindall, and Morton (2010) suggest that traditional media pitching will always play a role in public relations. But, the Internet is changing the way media pitching occurs and influences the process of agenda setting and agenda building in the media.

For example, the social media new release has gained attention in the media industry. The social media news release was launched in 2006 by Todd Drefen of SHIFT Communications (Waters et al., 2010). The release is an email pitch that allows "readers and observers to interact, contribute, and build on the content presented by 
organizations," as well as to attach multimedia and other documents to the email pitch (2010, p. 247). Another example of the social media release is HARO (Help A Reporter Out), which was created in 2007 by Peter Shankman as a group on Facebook.com (Waters et al., 2010). This group "encouraged journalists to toss specific information requests to the group" and allowed both professional communicators and everyday people to become the source (p. 248, 2010). Due to the popularity of this source, HARO has since moved onto Twitter and mass email messages. HARO now has " 80,000 sources and 30,000 journalists, and issues 3,000 queries per month" (p. 249, 2010).

In addition to media relations, public relations practitioners are realizing that social media serve as useful tools for relationship management, environmental scanning, information dissemination, targeted messaging, and establishing a worldwide presence (Kent, 2008; Christ, 2005). Briones, Kuch, Lui, and Jin (2011) explain, "social media is a useful tool for relationship management because it allows organizations to create a dialogue with audiences in real-time," as well as providing an opportunity for feedback (p. 1). Public relations practitioners and journalists are using blog archives to research background information on topics (Kent, 2008). In addition, social networking websites and blogs allow practitioners to easily track sentiments, responses to events or messages, and audience activities (Kent, 2008). Public relations practitioners have also begun approaching the blogging community to pitch stories (Waters et al., 2010).

On the other hand, some weaknesses have been recognized from using social media as a public relations tactic. If executed incorrectly, social media content can be seen as propagandistic, or simply be ignored by the audience (Kent, 2008). In addition, commenters can expose feelings and attitudes about topics and issues, which may 
prove helpful for practitioners. However, many commenters' do not represent the majority view of the audience. In fact, some blog commenters represent a fanatic and minority opinion (Kent, 2008). Lastly, the credibility and status of a blog or social networking forum can impact its influence on the intended audience (2008). According to M.L. Kent (2008), only 56 percent of bloggers make an effort to fact check, and 60 percent do not post corrections.

The credibility of the organization, media outlet, or individual behind a blog or social networking handle is important for public relations practitioners. A study by Sweetser, Porter, Chung, and Kim (2008) suggests journalists and public relations practitioners who read or write blogs likely find blogs to be more credible. However, journalists and public relations practitioners are utilizing blogs in two different ways. Practitioners are using blogs for non-interactive purpose (i.e., collecting information, surveillance, and research) while journalists are using blogs interactively by actively "writing work-oriented blogs" (Sweetser et al., 2008, p. 180). When it comes to social media content placed in traditional media, journalists initially rate "online information tools as less credible than the general public, but eventually report equal levels of credibility as uses increase" (Sweetser et al., 2008, p. 171). This suggests that journalists will soon find social media content to be more credible. Unfortunately, in public health agencies, there are overall low adoption rates for social media tools, according to a recent study (Avery et al., 2010).

\section{Agenda Setting and Agenda Building}

Because health is a popular topic in both traditional and new media, there are ample opportunities for health organizations to reach the public through these channels. 
Traditionally, health beat reporters relied heavily on information subsidies, such as from public relations practitioners at health organizations, for information on health news and developments (Len-Rios, Hinnant, Park, Cameron \& Frisby, 2009). This information may influence the type of health information received by the public, policy advocates, and health professionals. This is explained in the agenda-setting theory.

Agenda setting describes media influence on how the public perceives the importance of issues in the news (Len-Rios et al., 2009). In 1968, Maxwell McCombs and Donald Shaw (1972) hypothesized that the mass media have the power to influence the public's agenda. In their study, McCombs and Shaw examined the political issues covered in local newspapers and compared those topics to issues that the local public felt are important (1972). Findings suggested that the public's interests most often reflected the media's agenda; however, there is a known lag between the time the agenda is communicated and the time the public receives that agenda. Past media research has found "strong intermedia agenda setting effects between elite-to-less-elite traditional media entities" (Meraz, 2009, p. 684). In addition to influencing political media content, studies have suggested the media's agenda setting role for "scientific and risk communication, health care issues, health promotion, marijuana, chronic kidney disease, and emergency preparedness" (Wallington, Blake, Taylor-Clark, \& Viswanath, 2009, p. 488). According to Wallington et al., this past research highlights a crucial link between media agenda setting and the prioritization of issues in establishing effective health programming (p. 488). Since health and medical content have appeared largely on the Internet, there is also the potential for an agenda-setting effect on Internet content. 
In addition to the agenda setting theory, agenda building, which occurs prior to agenda setting, may also more directly influence the content of social media messaging and traditional media content. The agenda-building theory also began in political news research in 1977 with Cobb and Elder (2009). Agenda building refers to how news items get on the media agenda while others do not. Another approach to media issue perceptions is framing, which explains the ways in which media reports select and highlight particular elements of an issue (Entman, 2000). Framing presents two "logically equivalent situations, where one is presented in positive or gain terms and the other in negative or loss terms" (Garcia-Retamero \& Galesic, 2010). In health communication, framing can occur through the mass media, health promotion, and healthcare professionals. Some examples of framing in health communication include explaining "chances of mortality versus survival from surgery" or focusing on the risks and disadvantages of not agreeing to a medical screening versus emphasis on the benefits or advantages (Garcia-Retamero \& Galesic, 2010, p. 1323). Past research suggests that gain frames are more effective in promoting disease prevention behaviors while loss frames are more effective in promoting disease detection (2010).

In 1986, Turk extended the theory of agenda building to the practice of public relations (Kuzma, 2010). Turk theorized that the sources of information, such as public relations professionals, "may have as much to do with the media's agenda as the selection processes of the journalists themselves" (Kuzma, 2010, p. 11). Patricia Curtin (1999) explains, "If practitioners can obtain media placement of their subsidies, then they influence the media agenda, which in turn can influence public opinion and the public agenda--a process that has come to be known as agenda building" (p. 54). 
Public relations professionals seek to shape the media agenda to favor their organizations. Because of this, health information provided to the public by the media may be affected by the health content public relations professionals are providing. Research on health news and agenda building has found that journalists rely more heavily on sources and experts in the health field to spark story ideas and to provide content (Wallington et al., 2009). Additional data have indicated that personal contacts with public relations spokespersons and news releases were the most frequently used sources of information by TV health reporters (Cho, 2006). Findings also estimate "that 40 to 50 percent ... of daily newspaper content originates from press releases" (Curtin, 1999, p.54). However, numerous other studies have found that journalists prefer autonomy of their news selection process and approximately 90 percent of press releases are never used (Curtin, 1999).

Nevertheless, social media influence may provide different data. In particular, social networking and blogging websites have become a primary way for public relations practitioners to influence individuals and their publics (Kent, 2008). These tools allow organizations to control what individuals see, while gaining trust, empathy, and giving individuals the ability to participate in content (Kent, 2008). Studies have shown that "most broadly, the stories and issues that gain traction in social media differ substantially from those that lead in the mainstream press" (Pew Research Center, 2010). A study by the Pew Research Center found that after tracking the content of 49 weeks of traditional news and blogging platforms, "blogs shared the same lead story with traditional media in just 13 of the 49 weeks studied" (Pew Research Center, 2010). The study also found that social media and traditional agendas often differ from one 
another (para. 14). However, blog content relied heavily on the traditional press for information (para. 14).

It is common for blogs to cite mainstream media in their posts. Yet, the same is not true for mainstream media outlets. However, there has been no research conducted on the interplay between traditional media and blogs in reference to healthcare beats and blogs specifically. Research conducted on the intermedia influence of blogs has focused largely on politics. A study by Langosa (2008) found that political blogs tend to rely heavily on media sources for information, but the reverse was not true for the newspapers or television outlets in the study. He found that source attribution in news stories had little to no impact from blogs (Langosa, 2008).

\section{The CDC, Public Health, and the Internet}

Governmental organizations serve an important role in facilitating health promotion and communication to the U.S. public. E-health is being used to promote health news and change behaviors. The CDC has embraced e-health technologies and strategies, using social media to provide users access to credible, science-based health information (Centers for Disease Control and Prevention, 2010a). The CDC is a major operating component of the Department of Health and Human Services.

In 2010, CDC.gov received approximately 553,355,542 page views, which was a 39 percent decrease from 2009 (Centers for Disease Control and Prevention, 2011d, para. 1). The majority of CDC.gov users are women (69\%) who range in age from 35 to 64 years old $(70 \%)$. Data also showed that "visitors to CDC.gov who interact with CDC's social media are 2 points more satisfied (82) than those who do not (80)" (CDC.gov Metrics: January 2011). Currently, the CDC utilizes a number of social media forums 
and tools to connect with their public, including Twitter, Facebook, MySpace, DailyStrength, YouTube, Flickr, iTunes, blogs, widgets, e-games, e-cards, badges and buttons, virtual communities such as SecondLife, and mobile texts.

The CDC is using a combination of public relations tactics in their program called Vital Signs. This program, launched in August 2010, is similar to the social media news releases, using many e-tactics such as a Morbidity and Mortality Weekly Report (MMWR) Early Release, "a fact sheet, website, a media release, and a series of announcements via social media tools" (Centers for Disease Control and Prevention, 2011a, para. 1). Vital Signs is released the first Tuesday of every month. According to it's website, the "CDC believes that by focusing on a single topic using multiple media devices, the states might better identify these health problems in their area and work towards their improvement" (2011a).

In addition to this multifaceted public relations approach, the CDC promotes nine blogs with topics ranging from occupational health to HIV prevention and control (Centers for Disease Control and Prevention, 2010b). According to the CDC's social media toolkit, the CDC use their blogs "to share content in a way that allows readers to leave comments and engage in discussion" and to give their topic or program a more personal and engaging presence than a website allows (Centers for Disease Control and Prevention, 2010a, p. 36).

The importance of social media in providing accessible health information to the public is clear. Important research has been conducted on the health content of these social media tools, the importance of traditional and social media in public relations, and the characteristics of social media writers and readers. However, there remains a 
research gap on how these new media forms influence the mainstream news agendas and public relations strategies in health communication. This study aims to help fill this void in research. 


\section{Research Questions}

As made evident, the field of health communication has multiple facets. However, there has been no conclusive research on the agenda-building effect of social media tactics, traditional tactics, and the mainstream media in health communication. There has also been no critical analysis of social media's influence on public relations strategies and tactics in the health care realm. Owing to this research void and review, the following research questions have been created:

RQ1: How does the CDC use their social and traditional media strategically to reach the media and its publics?

RQ2: What topics (i.e., agendas) are discussed through the CDC's primary social media tactics?

RQ2a: What topics are discussed in the CDC's Twitter account (i.e., @CDCgov)?

RQ2b: What topics are discussed in the CDC's social media release (i.e., Vital Signs)?

RQ3: What topics (i.e., agendas) are discussed in the CDC's primary traditional media tactics during the same period?

RQ3a: What topics are discussed in the CDC's press releases?

RQ3b: What topics are discussed in the CDC's media advisories?

RQ4: Is there an association between the CDC's social media (i.e., Twitter and Vital Signs) and traditional media (i.e., press releases and media advisory) topics (agendas)? 
RQ5: Are these health topics (agendas) subsequently appearing in national media (i.e., Associated Press) during the study?

RQ5a: Are the social media topics appearing in Associated Press stories? RQ5b: Are the traditional media topics appearing in Associated Press stories?

RQ6: Is there an association between the CDC's media topics and AP topics during the study? 


\section{Method}

\section{Overview of Method}

The objective of this research was to discover what health messages were being disseminated through the CDC's communications channels, as well as if these messages had any agenda-building effect on mainstream media placement. In addition, this research sought to discover CDC professionals' sentiments about communication strategies and tactics at the CDC. Initially, this study sought to look at agenda-setting level two, which would have included the CDC's health topics and the frames of these topics. However, due to the time constraints of this thesis, it was determined that agenda-setting level one was more feasible, which focuses only on the health topics in CDC messaging. This study is divided into two phases, including both qualitative and quantitative research. A multi-method approach was chosen because using triangulation in research decreases the likelihood of deficiencies and biases that stem from a single method (Goodwin \& Goodwin, 1984).

In the first phase, personal interviews with CDC public relations professionals were conducted to discover any public relations strategies regarding media tactics and message dissemination used by the CDC. Qualitative interviews are "useful for identifying data needed to explore a problem" and "reveal attitudes, motives and behaviors" (Zhou \& Sloane, 2009, p. 290). In the second phase, three separate content analyses were conducted to assess the CDC's social media agenda, the CDC's traditional media agenda, and the Associated Press (AP) media agenda to look for any agenda building or intermedia agenda-setting effects. The specific social and traditional CDC tactics sampled in this study were determined by the results of the personal 
interviews in phase one. Content analyses have been chosen because this method is useful to summarize and describe large bodies of communication messages (Zhou \& Sloan, 2009). Content analyses also allow researchers to systematically study change over time (Zhou \& Sloan, 2009).

\section{About the CDC}

This study focused on the Centers for Disease Control and Prevention (CDC) because of its health expertise and prominence in the United States as a major operating component of the Department of Health and Human Services (Centers for Disease Control and Prevention, 2011c). The CDC's mission is "to collaborate to create the expertise, information, and tools that people and communities need to protect their health - through health promotion, prevention of disease, injury and disability, and preparedness for new health threats" (Centers for Disease Control and Prevention, 2011c, para. 2).

The CDC is composed of several Centers, Institutes, and Offices (CIOs) who implement CDC response "in their areas of expertise, while also providing intra-agency support and resource-sharing for cross-cutting issues and specific health threats" (Centers for Disease Control and Prevention, 2011c, p.1). Each CIO has a separate Director, Associate Director, and subsequent communications professionals with varying responsibilities. However, the Office of the Director oversees all communications professionals within the CDC. A breakdown of the CDC's organization can be found in Appendix F.

The CDC has a central communications office under the Office of the Director (OD) level, called the Office of the Associate Director for Communication. This office 
includes the Division of News and Electronic Media, where the Social Media Team sits, as well as the Vital Signs campaign. Because this central communications office has no specific health topic expertise, communication professionals working in this office rely on the experts at specific Centers, Institutes, and Offices (CIOs) to send messaging to be disseminated on the main CDC social media and web channels, in addition to each CIO's topic-specific media channels.

\section{Qualitative Approach}

In phase one, the author conducted two interviews with health communications specialists at the CDC over the phone for convenience. The researcher was also in contact with a third CDC professional via email. The qualitative analysis identified tactics to be analyzed quantitatively in phase two.

\section{Protocol.}

An interview guide, included as Appendix A, was developed prior to the interviews to "provide the interviewer with the order and wording of specific questions" (Zhou \& Sloan, 2009, p. 300). The interview guide also ensured that all participants were asked the same questions, the direction of the interview remained focused (Zhou \& Sloan, 2009), as well as ensured redundancy in the questions to check for consistency in answers (Rubin \& Rubin, 2005). The interview began with a brief introduction of both the interviewer and interviewee and with easy, broad questions. More descriptive questions followed and the interview concluded with easy questions.

A pilot interview was conducted prior to the thesis proposal with Kimberly Walker, Director of Communications at WVU's P.I. Reed School of Journalism. Walker oversees 
all School of Journalism communications, which uses both social and traditional media public relations tactics. This interview was used to refine the content of the interview questions, follow-ups, and guide organization, as well as to ensure that the interview did not exceed 30 minutes. In this pretest, the interview lasted only 19 minutes.

Recruitment and Participants.

This study pursued participants currently employed at the CDC whose day-to-day tasks directly involve working with media (i.e., traditional, social, web). These participants were ideal because they possess first-hand knowledge of CDC campaign implementation, messaging, and day-to-day media functions. To identify interview participants, emails were sent to senior-level communications members at the CDC, in a snowball sample fashion, to identify two to three appropriate communication contacts. Because the CDC is a large entity, senior-level professionals in communications roles were first identified via the CDC website and contacted first due to their familiarity of CDC communications and media employees. Once emails were sent, senior-level professionals distributed the study information to appropriate contacts, who responded directly to the researcher. Interested CDC communications professionals were then emailed to confirm an interview date.

Two participants were identified by the snowball method through senior-level leadership in the Division of News and Electronic Media at the CDC. The third participant answered remaining questions about Vital Signs and was identified by the other interviewees. Each participant works with varying media specialties, which provides a wide outlook on the communications strategies and strengthens data credibility. 
The first interview was conducted with Jessica Schindelar on November $14^{\text {th }}$, 2011, and lasted approximately 23 minutes. Schindelar is a Health Communication Specialist on the CDC's Social Media Team in the Division of News and Electronic Media, under the Office of the Associate Director for Communications. The second interview was conducted with Margaret Silver on November $16^{\text {th }}, 2011$, and lasted approximately 24 minutes. Silver is a Health Communications Specialist in the Office of Public Health Preparedness and Response. Silver works closely with all aspects of communications, including media relations, social media, events, and web-based communications. Lastly, email correspondence with Diane Brodalski was conducted in mid-December of 2011. Brodalski is a Social Media Specialist for Northrop Grumman in the Division of News and Electronic Media, under Office of the Associate Director for Communication. Brodalski also works closely with the CDC social media release Vital Signs.

\section{Consent and Confidentiality.}

The author received verbal consent from participants to record the interviews for the convenience of analysis, as well as to include participants' names in the final thesis. The author also disclosed that the results of this study would be shared with participants once completed. Lastly, it was emphasized that any participant desiring anonymity may have their names redacted from the final thesis, if desired.

\section{Data Analysis.}

Prior to any data analysis, the interviews were transcribed in a Word document starting at the beginning of interview questioning. After transcription, analysis occurred by examining transcripts line by line to identify emerging themes in participants' 
answers, per protocol outlined by Rubin and Rubin (2005). Notes and highlights were made throughout this analysis to track the researcher's thoughts, exceptional quotes, and emerging themes. After this analysis occurred, the interviews were compared to discover similarities and differences in themes and opinion. Follow-up questions were sent via email to participants to clarify topics or statements to ensure accuracy. Email correspondence was included in the overall analysis. Email correspondence and complete transcripts of the interviews appear in Appendix B and C, respectively.

\section{Quantitative Approach}

In the second phase, three separate content analyses were conducted to assess and compare the agendas of the CDC's social media, the CDC's traditional media, and the Associated Press (AP) to seek evidence for agenda building and/or CDC intermedia agenda-setting effects. The specific tactics to sample were determined by the results of the personal interviews in phase one. These mediums included tweets and Vital Signs releases for CDC social media, press releases and media advisories for CDC traditional media, and AP articles to represent the national agenda.

To examine the main agenda of these tactics, the prominence of a health topic in the headline and lead paragraph of a release or advisory and the content of a tweet were identified using an emergent coding system, where topics (agendas) were identified as found in each unit (Martinelli \& Mucciarone, 2007). As these health topics emerged, this determined the main health agendas of each sampling unit. Once the main agendas were found and analyzed, health categories were logically created. 
CDC Sample.

All CDC media sampling frames included content from a six-month period beginning February 1, 2011, and ending July 31, 2011. This time period was chosen to accommodate a convenient time frame for the researcher and a manageable data pool. This time frame also avoids seasonal health topics such as the flu and common cold. The unit of measure for all CDC content analyses was the main health topic.

The sampling units for the social media analysis include the individual @CDCgov tweets and Vital Signs media releases posted on the CDC website. The study's social media sample employed a total of 606 tweets $(\mathrm{N}=918)$ from @CDCgov and 6 Vital Signs issues, including one for each month in the sample. The method for obtaining the tweets was by manual extraction from the CDC's Twitter page.

Although the CDC maintains several Twitter feeds, the researcher only considered @CDCgov tweets because this account disseminates a broad range of health topics from many CIO's within the CDC. As previously noted, Vital Signs includes the Morbidity and Mortality Weekly Report Early Release, a fact sheet, website, media release, and a series of announcements via social media tools (CDC Vital Signs, 2011). Vital Signs topics were pre-determined by CDC senior level leadership and rotate each month of the year. Because these topics have already been set and determined per each month, it was not necessary to content analyze these sampling units, as the health topic was already known.

The social media sample did not include automatic or manual retweets or any replies (@) to other users. (An automatic retweet is used when a user clicks on the "Retweet" button below a tweet. A manual retweet is when a user copies and pastes a 
tweet and signifies an "RT" in the tweet to show that another user wrote the tweet.) These tweets were not included in the sample because they are not written by @CDCgov, and therefore aren't directly correlated to the Twitter handle's messaging. Likewise, replies on Twitter were not included for the same reason. In addition, these tweets can be conversational in nature and do not always emphasize a health topic.

The traditional media sampling units are the individual press releases and the media advisories released during the study period. This content was also manually extracted from the CDC's Newsroom website. The study included a total of 52 traditional CDC messages: 37 press releases and 15 media advisories.

\section{CDC Coding Scheme \& Categories.}

There were three coding sheets and instructions for this content analysis. The first coding sheet focused on the CDC's tweets and discovered 1) the date, 2) the main health topic, and 3) the hashtags included, if any. Including the date of the tweet allowed the researcher to track the frequency of topics emerging during the study period. According to Twitter, "the \# symbol, called a hashtag, is used to mark keywords or topics in a Tweet" (Twitter, 2012). Hashtags were created by users to categorize and search Twitter messages (2012). Tracking hashtags in tweets allows the researcher to see what keywords the CDC has determined as important for their Twitter followers to use in searching for health terms.

The second coding sheet focused on CDC press releases, media advisories, Vital Signs releases, and AP articles, and tracked 1) the date, 2) the headline, and 3) the main health topic of the piece as a quick way to identify the main topic (agenda). The content analysis was determined through an emerging coding approach using key 
terms pulled from the medium itself. Therefore, no categories were set prior to initial coding of CDC materials. The last coding sheet was for AP articles and included a list of all health topics/categories previously discovered, explained below.

\section{AP Sample.}

Once the CDC content analyses were completed, data were analyzed to determine the frequency of health topics, as well as to organize emerged topics into health categories. These found health topics were then compared to topics found in the mainstream media to discover if there was any association. The AP has been selected to sample due to its national distribution as the top newswire service. The AP is a 24hour continuously updated news service with more than 300 locations worldwide (AP, 2011). Because of this, the AP will serve as a mainstream news source that is likely to widely circulate health stories.

The population of messages was the Associated Press (AP) news articles $(\mathrm{N}=183)$ from the same time frame: a six-month period beginning February 1, 2011 and ending July 31,2011 , plus an additional two weeks after this sample, extending until August 14, 2011, to account for a possible lag in the news cycle. The sampling unit is the individual news story and the headline and lead paragraph were used to determine the primary agenda stories.

The news stories were retrieved through the LexisNexis database, which was accessed via West Virginia University Libraries. To locate the AP stories, the terms "CDC" and "Centers for Disease Control" were searched in LexisNexis during the timeframe discussed above, plus two weeks to allow any delayed coverage, and compared against these health categories. This search resulted in 153 articles and 
served as the basis for the AP article sample.

\section{AP Coding Scheme \& Categories.}

The AP story coding sheet (Appendix D) is similar to the CDC coding sheet, which tracked 1) the date, 2) the headline, and 3) the main health topic(s) of the piece. Because the health categories emerged from the CDC content analysis, this coding sheet included 48 specific health categories to select. A list of the non-collapsed health categories can be found in Appendix E. Each article was assigned only one health topic. The presence or absence of CDC-generated health topics was the main dependent variable of interest.

\section{Data Analysis}

Data analysis was conducted using SPSS 18 . There were a total of 811 messages in the population analyzed. The sample included CDC messaging: tweets (74\%), Vital Signs issues (0.7\%), press releases (4.6\%), and media advisories (1.8\%). From the four CDC media samples, 48 health categories emerged. The 48 categories were later collapsed into 14 broader health categories for further data analysis.

Spearman's rho was used to analyze correlations of health categories between media. Because there were numerous cells with counts of fewer than 5 , and more importantly in this study, with cells counts of 0 , the chi square test was not a scientifically robust method of analysis. Spearman's rho is used with ordinal-level data and is "frequently used to determine how similarly two variables share common rankings" (Riffe, Lacy, \& Fico, 2005, p.192). This analysis allows the researcher to not only discover associations between two variables, but also determine the strength of 
association (2005).

\section{Coding Process and Reliability.}

Prior to proposal defense, the author conducted a pretest to assess the validity of the codebook and coding sheet. The coding sheets, instructions, and codebook appear in Appendices D and E. Pretest materials were selected from August 2010, as this was the first month Vital Signs was available. During this pretest, several edits were made to both the codebook and coding sheet. It was determined that the codebook was in need of more space for writing, clear phrasing and specific explanations, and examples of topics to be better understood and utilized by the coders.

The author and another graduate student conducted two additional pretests to assess the rigor and validity of the coding scheme. The initial pretest examined the intercoder reliability of the topic emergence for the CDC's social media and traditional media tactics. This initial pretest was conducted prior to any data analysis and category determinations to ensure that health topics were similarly being interpreted. A randomly selected subsample of 86 communications materials ( $>10 \%$ of total $N$ ) was examined in this pretest. Data in the subsample were drawn from the original sample and used in data analysis. This subsample included 30 percent of CDC press releases $(N=11)$, media advisories $(\mathrm{N}=5)$, and Vital Signs issues $(\mathrm{N}=2)$, in addition to 10 percent of CDC tweets $(\mathrm{N}=68)$. This initial pretest provided $91.8 \%$ agreement between two coders using simple agreement. Because this research seeks to compare agendas within the CDC to the mainstream media (AP), analysis of CDC content was conducted prior to looking at the AP sample. The coders met for two training session to become familiar with the coding scheme, including full explanations and examples of CDC messaging and health 
topics.

A second pretest was conducted after CDC health topics had emerged and been separated into the 48 non-collapsed categories. Intercoder reliability was assessed for only the AP content analysis, using the non-collapsed health categories and a subsample of 10 percent $(\mathrm{N}=15)$ of the AP articles. Intercoder reliability for the AP materials was $91.3 \%$ using simple agreement. 


\section{Results}

\section{Interview Results}

\section{RQ1: How does the CDC use their social and traditional media strategically to reach the media and its publics? \\ CDC Organization and Communications.}

The participants discussed the decentralized nature of the communications offices at the CDC, which affects the way messages are disseminated across the agency. (CDC's organizational chart appears in Appendix F.) In addition to the central communications office, each $\mathrm{CIO}$ at the CDC has its own communications office and develops its own communications plans, campaigns, objectives, target audiences, and reach. Each $\mathrm{ClO}$ is comprised of an Office of the Director (OD) and Associate Director (AD), respectively, and subsequent Divisions and Branches. The Communications Office is generally located in the OD. Each Office of the AD within a $\mathrm{CIO}$ includes titles such as the $A D$ of Communication, $A D$ of Learning, $A D$ of Financial Resources, etc. This varies slightly between the CIOs, but the concept of Associate Directors is consistent across the CDC.

In addition, each $\mathrm{ClO}$ varies in the staff dedicated to a particular medium (i.e., social media updates, events, media relations, etc.). For example, one participant's job functions include a wide variety of communications responsibilities including media relations, social media, internal communications, event planning, speech writing, campaign development, and research. This participant is also a member of the social media counsel at the CDC. To contrast, another participant working in a different $\mathrm{CIO}$ is involved strictly with social media messaging and providing expertise and guidance to 
other ClOs campaigns at the CDC.

\section{Communications Plans and Audiences.}

Similar to communications offices within the CDC, campaigns, communications objectives, and target audiences vary within each $\mathrm{ClO}$. Campaign objectives and goals are developed and set at the program level. Generally, each $\mathrm{ClO}$ develops its own plan and tactics to complement that plan. A participant in the Office of Preparedness and Response explained its campaigns generally involve social media, web-based media, and interaction with mainstream media contacts. These campaigns may include talking points or issues and key messages adapted to each medium. Another participant, working on the Social Media Team, explained that since the Office of the Associate Director for Communications does not have a topic of expertise, their involvement in campaigns is very different. The participant stated, "My primary role is to provide guidance, leadership, and expertise to different programs across the agency and how to incorporate social media into their overall communications campaigns."

Some target audiences do stay consistent across the CDC, while others differed between $\mathrm{ClOs}$ and their campaigns. All participants listed the "general consumer audience" and "public health professionals at the state, local, and federal levels" as target audiences. Conversely, the Office of Public Health and Preparedness focuses on the media and emergency health practitioners and emergency, in addition to the previously mentioned audiences. In the Office of the Associate Director, the Social Media Team listed healthcare providers as an additional target audience. Participants stated that social media messages generally cater toward the general consumer. However, the CDC is beginning outreach in targeted physician networks to reach 
healthcare providers specifically. These networks include both professional networks like the American Medical Association, Epocrates and Medscape, as well as targeted physician-only social networks such as Sermo and QuantiaMD.

\section{Messaging in Social Media vs. Traditional Media.}

The variance of $\mathrm{CIOs}$ and communications offices at the CDC also influences the implementation of social and traditional media tactics. Each office focuses on each tactic differently. A participant working on the Social Media Team explained that at the Office of the Director level, there are separate branches for traditional media or media relations and social media. Although the Social Media Team does not work directly with media contacts, some Social Media Team professionals work as liaisons to other branches and programs to manage and place their content, such as press releases or other campaign materials, on the main CDC social media channels.

In the Office of Public Preparedness and Response, health communication specialists perform a variety of communications tasks, with involvement ranging between both social media and traditional media tactics. In this $\mathrm{ClO}$, traditional media and media relations are executed by relying on the maintenance of personal contacts with the mainstream media to ensure media pick-up. A participant stated:

We have a few mainstream media contacts at CNN, NBC, the New York Times, and the Wall Street Journal, as well as Atlanta-based journalists. We'll send a quick email about an upcoming project or take them out to coffee. We maintain a certain level of relationship so when we do have something coming up the pipe, they trust us and we trust them.

The participant later emphasized that their Office does not often rely on the press release. The participant stated, "Sometimes we'll develop something for the CDC main 
page's "In the News" section. But for the most part, it's our office and we'll identify what our key messages are and ... send them out kind of in our own channels." According to this $\mathrm{ClO}$, mainstream media pick-up often occurs through the social networking websites Twitter or Facebook. The participant stated, "If we put stuff out there, they'll pick it up. But we don't just blog about it or shoot an email. We will post it, then tweet and Facebook it, and it gets picked up that way. Then it's [the blog post] retweeted or direct messaged to others more often."

To further attest to the influence of social media on mainstream media pick-up, the participant explained the outcome of a recent "zombie apocalypse" campaign. After posting the campaign's initial blog post on a Monday, the CIO received only a small amount of feedback. The participant explains further:

But it wasn't until we tweeted about it [the zombie blog post] on Wednesday that we just got this flood of calls and our server crashed 10 minutes after our first tweet. ... Even though we just posted it online on Monday, it wasn't getting that much buzz until Wednesday morning FOX News, one of the first people to call because they'd seen this tweet and they weren't sure if we'd been hacked or not.

Social media are widely monitored and used at the CDC. As previously stated, the use of social networking websites and blogs are often times how the mainstream media access CDC messaging, according to the interviewees. According to a participant in the Office of the Associate Director (AD), each blog, Twitter handle, and Facebook page is updated and maintained by the CIO that owns that space. For example, the Office of Public Preparedness and Response updates the Twitter handle, @CDCReady, while the CDC Injury Center updates their own Twitter handle, @ CDCInjury, and Facebook page, CDC Emergency. Blogs are written in a similar manner. Each blog is housed within a particular $\mathrm{CIO}$ and focused on its health topic. 
Communications staff often write these blogs, as well as ghostwrite blog posts for senior-leadership. The overall communications office in the Office of the AD does not have a hand in the upkeep of these social media presences. However, they do maintain and update the main CDC social media pages, such as the main CDC Facebook page and the Twitter profile (@CDCgov).

Although there are differences between $\mathrm{ClOs}$, there are policies and guidelines in place at the CDC to ensure each office is sending appropriate messages. Specifically, there is the CDC Social Media Policy, which governs how professionals develop and approve messaging prior to disseminating it on the Internet. According to a participant, "Each $\mathrm{ClO}$ should have a [social media] plan in place and clear their messages through the appropriate management; this means either their $A D$ for Communication or their $A D$ for Science and Communication." Communicators often have a pre-approved list of tweets or Facebook updates that can be sent out at any time, and are generally supported by a campaign plan or other larger goals. However, if a communicator creates a message "on the fly," the CIO's AD must approve it prior to being sent. A participant explains further:

For example, in emergency preparedness, we have pre-cleared tweets on a lot of different natural disasters because we know they will inevitably happen at some point. Or certain times of the year, when it's emergency preparedness month, we'll have pre-cleared tweets ... In terms of ones we make up on the fly, our ADC (Associate Director of Communications) is very laid back and very trusting of us. But it could be five minutes or it could be a day depending on your director.

\section{Vital Signs.}

The interview participants did not have direct contact with the Vital Signs report in their daily routines, but did have knowledge on the development of the release. In 
addition, one participant shared more detailed information on the monthly release via email. According to participants, Vital Signs topics are pre-determined and rotate each month of the year. A participant on the Social Media Team explains:

The Vital Signs release is a little bit more of an agency-wide effort. The Vital Signs product is managed out of our Office of the Director level. They work with different programs to develop the key messages and all of that stuff. ...We have a staff member on my team that is dedicated to working with the programs each month to develop their social media strategy for that release.

Many of these topics have been defined as "winnable battles." According to a participant, winnable battles "address the leading causes of death and disability" and "are evidence-based interventions that exist and can be broadly implemented and CDC's intensive focus and efforts can have a significant impact in a short period of time." The CDC's Director, Dr. Frieden, and other senior level leadership selected these topics.

Because Vital Signs topics are set per each month of the year and do not change, it was not necessary to include them in a content analysis. These topics include:

- Motor Vehicle Safety in January, and is defined as winnable battle

- Cardiovascular Disease in February

- Healthcare-Associated Infections in March, and is defined as winnable battle

- Teen Pregnancy in April, and is defined as winnable battle

- Asthma in May

- Food Safety in June, and is defined as winnable battle

- Cancer in July

- Obesity in August, and is defined as winnable battle

- Tobacco in September, and is defined as winnable battle

- Alcohol in October

- Prescription Drug Overdose in November

- HIV in December, and is defined as winnable battle 
There are three key audiences for the Vital Signs releases: the general consumer, public health practitioners, and healthcare providers. The framework of each Vital Signs release is also the same each month. A participant explains that each release discusses "what we can do as an individual in this topic area, what public health practitioners can do, and what policy-makers or healthcare providers can do to impact the topic."

\section{Measurement and Evaluation.}

In terms of measurement and evaluation of campaign messaging, participants emphasized the importance of monitoring every campaign. A participant stated that in social media, her $\mathrm{CIO}$ is often looking at trends in followers and engagement, growth, traffic back to the website from social media properties, click-throughs, page views on blogs, and the number of comments on social media pages. Another participant emphasized tracking the number of mentions through social media outlets and articles being written, as well as marketing saturation.

To track these messages, the CDC pays for several programs that aid communications professionals in accessing metrics and measurement for their campaigns. Some of these programs include Cision, Radian 6, and Adobe's Omniture. Cision and Radian 6 both monitor social and traditional media messaging. Radian 6 is a new program used by the CDC and is used for tracking the organic growth of a campaign.

Only one participant discussed how a particular $\mathrm{ClO}$ seeks to evaluate the success and reach of a campaign's key messaging. This participant explained, "We are exploring how to best measure the impact of social media messaging from a health 
perspective." Surveys are often used to measure user satisfaction and audience sentiment, such as user satisfaction with information provided on CDC profiles or the frequency with which the CDC posts on these profiles. Evaluation surveys also identify user characteristics and what these users are doing with the information they find through CDC web properties. Both participants emphasized the impact of Twitter on message dissemination over channels such as Facebook or CDC blogs. A participant stated, "I know from our audience surveys that we probably have a little bit more of a media audience on our Twitter profiles than say, on our Facebook profiles." However, the same participant stated, “We don't see as much interaction on our Twitter profiles as we do on our Facebook."

Impact of Social Media on the Health Agenda.

Interviewees attested to the growing importance of social media on the nation's health agenda. The participants agreed that there is more health information both online and in print, and this information is easy to access. Because of this, the CDC has a responsibility in helping the public sift through this information to provide the most credible sources. By doing so, social media "allow agencies like the CDC to get into the conversation," said one participant. To further explain:

There's a lot of people blogging about it [health], there's a lot of people with Facebook pages, or commenting on Twitter about it. And having these things allows us to get into the conversation and direct people to resources from a reliable source that explains what the risks are with these different vaccines or other health-related topics.

Another participant explained that the CDC has a large amount of health information available online. This can often seem daunting to users looking for something specific. 
The participant explained that "social media allow us to feed health information into those spaces, where it was just sitting on our website before. It's raising its importance."

\section{Common Themes and Differences.}

Overall, the interviews discovered several themes that were consistent amongst the interviewees. First, the decentralization of the communications departments in all CIO's at the CDC was apparent throughout all the interviews. In addition, although each participant was involved in differing aspects of health communication at the CDC, the way in which each participant described the process of planning, approving, disseminating, and evaluating campaign messaging was largely similar. All participants also attested to the importance of social media in campaign messaging and the national health agenda. Most importantly to this study, each participant emphasized the importance of Twitter messaging for garnering media attention for the CDC, while speaking less about the importance of blogs in this sense. However, differences did arise amongst participants regarding target audiences at the CDC. Participants did not always mention the media as a target audience. There were other variations in target audiences depending on the $\mathrm{CIO}$ within the CDC.

\section{Content Analysis Results}

The content analysis was designed to answer five broad research questions, in addition to six, more specific sub-questions. The research questions intend to discover the health topics most discussed within each CDC medium, using an emergent coding approach. Because there were a number of cell counts of fewer than 5 , which can be problematic in chi square analysis, especially in smaller contingency tables, topic categories were logically combined/collapsed into 14 categories from the original 48 to 
further explore possible topic (agenda) associations. In this section, each research question is analyzed based on the results of the content analysis using these defined categories. Listed in Table 1 are the 14 collapsed health categories with their more specific subtopics $(\mathrm{N}=48)$ :

Table 1: Description of the 14 Health Categories

\begin{tabular}{|c|c|}
\hline Health Category & Description \\
\hline $\begin{array}{l}\text { 1. Environmental } \\
\text { Health }\end{array}$ & $\begin{array}{l}\text { a. Recycling } \\
\text { b. Animal handling } \\
\text { c. Outdoor disease or infection } \\
\text { d. Water safety and health } \\
\text { e. Toxic substances and contaminants (often highlighted under the } \\
\text { term "ATSDR" or the Agency for Toxic Substances and Disease } \\
\text { Registry) }\end{array}$ \\
\hline 2. Injury Prevention & $\begin{array}{ll}\text { a. } & \text { Falls } \\
\text { b. Poisoning } \\
\text { c. Risk behaviors } \\
\text { d. Suicide } \\
\text { e. Traumatic brain injuries (TBIs) } \\
\text { f. Extreme weather illness } \\
\text { g. Motor vehicle injuries } \\
\text { h. Violence, abuse, and maltreatment (such as in the elderly and } \\
\text { children) }\end{array}$ \\
\hline 3. Disease Prevention & $\begin{array}{l}\text { a. Immunization/vaccines (including but not limited to polio, } \\
\text { measles, rabies, tetanus in all age groups) } \\
\text { b. Obesity } \\
\text { c. Tobacco (cessation, smoke-free laws, control) }\end{array}$ \\
\hline $\begin{array}{l}\text { 4. Specific } \\
\text { Diseases/Disorders/ } \\
\text { Disabilities }\end{array}$ & $\begin{array}{l}\text { a. Chronic disease (cancer, arthritis, blood disorders, STDs, } \\
\text { diabetes) } \\
\text { b. Disabilities (Tourette's, muscular dystrophy, disabilities data, } \\
\text { blindness) } \\
\text { c. Diseases (ALS, measles, hepatitis, tuberculosis) } \\
\text { d. Heart health (high blood pressure or cholesterol, stroke, heart } \\
\text { disease) } \\
\text { e. Other (meningitis, dengue, Scarlett fever, etc.) }\end{array}$ \\
\hline
\end{tabular}

(Table 1 continues on the next page.) 


\begin{tabular}{|c|c|}
\hline 5. Family Health & $\begin{array}{l}\text { a. General teen, child, women, men's health } \\
\text { b. Teen pregnancy }\end{array}$ \\
\hline $\begin{array}{l}\text { 6. CDC Twitter } \\
\text { Promotion (specific } \\
\text { to Twitter only) }\end{array}$ & $\begin{array}{l}\text { a. Surveys, contests, video/social media promotion } \\
\text { b. General Twitter conversation }\end{array}$ \\
\hline $\begin{array}{l}\text { 7. Birth Defects \& } \\
\text { Developmental } \\
\text { Disabilities }\end{array}$ & $\begin{array}{l}\text { a. Birth defects (hearing loss, spina bifida, heart defects, etc.) } \\
\text { b. Developmental disabilities (autism, cerebral palsy, etc.) } \\
\text { c. Mention of the National Center on Birth Defects and } \\
\text { Developmental Disabilities (NCBDDD) }\end{array}$ \\
\hline $\begin{array}{l}\text { 8. Food Health and } \\
\text { Safety }\end{array}$ & $\begin{array}{l}\text { a. Food safety and handling } \\
\text { b. Samonella, e.Coli, and other bacteria } \\
\text { c. Healthy eating }\end{array}$ \\
\hline $\begin{array}{l}\text { 9. Healthcare- } \\
\text { Associated } \\
\text { Infections }\end{array}$ & $\begin{array}{ll}\text { a. } & \text { Central-line bloodstream infections } \\
\text { b. } & \text { MRSA } \\
\text { c. } & \text { Surgical infections }\end{array}$ \\
\hline $\begin{array}{l}\text { 10. Public Health } \\
\text { Resources/Data }\end{array}$ & $\begin{array}{l}\text { a. Health reports or research with no specific health topic given } \\
\text { b. Public health advances, agencies, services } \\
\text { c. Global health } \\
\text { d. Public Health Informatics }\end{array}$ \\
\hline $\begin{array}{l}\text { 11. Emergency } \\
\text { Preparedness }\end{array}$ & $\begin{array}{l}\text { a. Radiation emergencies } \\
\text { b. Natural disasters and extreme weather } \\
\text { c. Emergency responders }\end{array}$ \\
\hline $\begin{array}{l}\text { 12. Antimicrobial } \\
\text { Resistance }\end{array}$ & $\begin{array}{ll}\text { a. } & \text { Antibiotics } \\
\text { b. } & \text { Drug resistance }\end{array}$ \\
\hline 13. Other & a. A health topic that does not fit within any of the above categories. \\
\hline 14. News & $\begin{array}{l}\text { a. This category is associated with AP stories only. This category } \\
\text { includes articles where the story is not about a particular health } \\
\text { topic, but may discuss health more generally; } \\
\text { b. OR the story does not discuss a specific health topic and cannot } \\
\text { be placed in any other category. }\end{array}$ \\
\hline
\end{tabular}

It is important to note that any associations found were discovered using the noncollapsed data of the 48 specific health categories. There were no associations present using the 14 collapsed categories. Because the collapsed categories were not as defined, there was less room for exact associations to be present. The use of the 14 
collapsed health categories did not result in statistically significant findings between or among media in this study.

Table 2 represents the overall frequencies and percentages of the 14 collapsed categories.

Table 2: Overall Collapsed Frequencies

\begin{tabular}{|l|l|}
\hline Health Topic & Frequency \\
\hline Environmental Health & $6.3 \%(51)$ \\
Injury Prevention & $6.9 \%(56)$ \\
Disease Prevention & $8.3 \%(67)$ \\
Specific Diseases/Disorders/Disabilities & $27.5 \%(223)$ \\
Family Health & $4.8 \%(39)$ \\
CDC Twitter Promotion & $7.5 \%(61)$ \\
Birth Defects and Developmental Disabilities & $16.2 \%(131)$ \\
Food Health and Safety & $8.0 \%(65)$ \\
Healthcare-Associated Infections & $1.8 \%(15)$ \\
Public Health Resources and Data & $4.8 \%(39)$ \\
Emergency Preparedness & $1.1 \%(9)$ \\
Other & $1.2 \%(10)$ \\
News & $5.5 \%(45)$ \\
Total & $\mathrm{N}=811$ \\
\hline
\end{tabular}

Table 3 (below) represents the overall frequencies and percentages of the 48 specific (non-collapsed) topics (agendas). 
Table 3: Overall Non-Collapsed Frequencies

\begin{tabular}{|c|c|}
\hline Health Topic & Frequency \\
\hline Recycling & $1.1 \%(9)$ \\
\hline Animal handling, outdoor disease/infection & $1.5 \%(12)$ \\
\hline Water safety and health & $2.8 \%(23)$ \\
\hline Toxic substances/contaminants & $0.9 \%(7)$ \\
\hline $\begin{array}{l}\text { Falls, poisoning, risk behaviors, suicide, TBI, } \\
\text { extreme weather illness }\end{array}$ & $3.5 \%(28)$ \\
\hline Motor vehicle injury & $1.6 \%(13)$ \\
\hline Violence, abuse, maltreatment & $1.2 \%(10)$ \\
\hline Elder population abuse/disparities & $0.6 \%(5)$ \\
\hline International travel & $0.6 \%(5)$ \\
\hline Teen pregnancy & $1.6 \%(13)$ \\
\hline Cancer & $3.2 \%(26)$ \\
\hline Arthritis & $0.2 \%(2)$ \\
\hline Other chronic disease & $1.1 \%(9)$ \\
\hline Asthma & $1.4 \%(11)$ \\
\hline Family health (general, teen, child, parenting) & $2.0 \%(16)$ \\
\hline $\begin{array}{l}\text { CDC Twitter promos (surveys, contests, } \\
\text { communication, video) }\end{array}$ & $7.5 \%(61)$ \\
\hline National health data (no specific health topic listed) & $0.9 \%(7)$ \\
\hline Women's health & $1.2 \%(10)$ \\
\hline STD's \& sex & $5.7 \%(46)$ \\
\hline Sickle cell disease & $3.5 \%(28)$ \\
\hline Other: blood clots, Hemophilia, etc. & $0.6 \%(5)$ \\
\hline General NCBDDD, pregnancy & $5.4 \%(44)$ \\
\hline Autism & $4.9 \%(40)$ \\
\hline Cerebral palsy & $0.7 \%(6)$ \\
\hline Hearing loss in infants and children & $1.1 \%(9)$ \\
\hline Spina bifida & $0.2 \%(2)$ \\
\hline Other birth defects & $3.7 \%(30)$ \\
\hline Eye health & $0.4 \%(3)$ \\
\hline
\end{tabular}

(Table 3 continues on the next page.) 


\begin{tabular}{|l|l|}
\hline Food safety and foodborne illness & $5.2 \%(42)$ \\
Healthcare-associated infections (central-line, & $1.8 \%(15)$ \\
MRSA, surgical) & $1.5 \%(12)$ \\
Obesity & $2.8 \%(23)$ \\
Food health & $3.9 \%(32)$ \\
Grand Rounds (Public health) & $2.2 \%(18)$ \\
Tobacco & $1.1 \%(9)$ \\
Emergency preparedness & $1.2 \%(10)$ \\
Antimicrobial resistance & $3.9 \%(32)$ \\
Immunizations/vaccines & $0.9 \%(7)$ \\
Disabilities (Data by state, Tourette's, muscular & \\
dystrophy) & $1.0 \%(8)$ \\
ALS & $1.1 \%(9)$ \\
Measles & $0.6 \%(5)$ \\
Hepatitis & $1.2 \%(10)$ \\
Tuberculosis & $1.8 \%(15)$ \\
Diabetes & $2.3 \%(19)$ \\
Heart health/disease & $2.5 \%(20)$ \\
Other, i.e. meningitis, dengue, Scarlett, etc. & $3.0 \%(24)$ \\
Other & $2.6 \%(21)$ \\
News & $\mathrm{N}=811$ \\
Total & \\
\hline
\end{tabular}

Overall, the five most discussed health topics included Specific Diseases/Disorders/Disabilities (27.5\%), Birth Defects and Developmental Disabilities (16.2\%), Disease Prevention (8.3\%), Food Health and Safety (8\%), and CDC Twitter Promotion (7.5\%). Because CDC Twitter Promotion includes only Twitter content, such as tweets about CDC surveys, contests, and video/social media promotion, and general Twitter conversation (such as celebratory holiday tweets), it was not included in this overall analysis. This category is not likely to garner any media attention from the 
national media. Therefore, the fifth most discussed health topic was Injury Prevention $(6.9 \%)$.

RQ2: What topics are discussed through the CDC's primary social media tactics?

The health topics most discussed among the CDC's social media tactics $(\mathrm{N}=606)$ were divided between the CDC's Twitter account, @CDCgov, and the CDC's monthly Vital Signs release. Because the Twitter sample $(\mathrm{N}=600)$ was exponentially larger than the Vital Signs sample $(\mathrm{N}=6)$, the overall health topics fell largely in line with Twitter topics. However, the CDC's social media agenda did discuss Specific Diseases/Disorders/Disabilities/STDs most often between Twitter and Vital Signs. Other topics in which both social media platforms discussed include Family Health, Food Health, and Healthcare-Associated Infections.

\section{RQ2a: What topics are discussed in the CDC's Twitter account (i.e., @CDCgov)?}

The top three most discussed topics on the CDC's Twitter account fell in line with the overall most discussed CDC topics: Specific Diseases/Disorders/Disabilities (28.7\%), Birth Defects and Developmental Disabilities (21.7\%), and CDC Twitter Promotion (10.2\%), as seen in Table 4. However, the CDC's tweets also discussed Disease Prevention (7.2\%) and Injury Prevention (6\%), which is different from the overall rankings. When compared to the 48 non-collapsed categories, CDC Twitter Promotion had the highest frequency. Specific health topics discussed often on Twitter was general NCBDDD topics (7.3\%), autism (6.5\%), and STDs and sex (5.7\%). The remainder of the health topics was discussed less than 5 percent of the time. 
Table 4: Frequency of Health Topics in @CDCgov Tweets

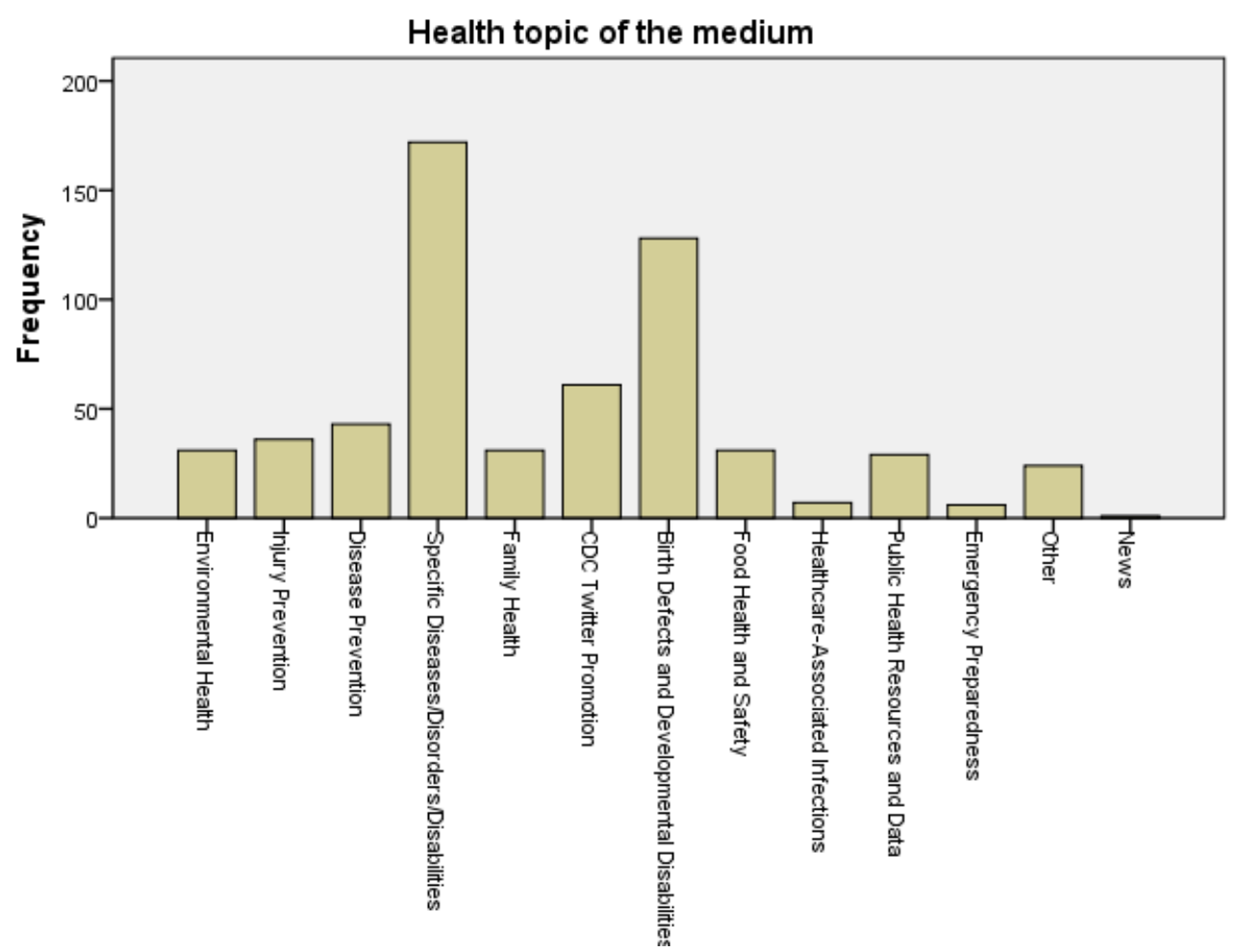

During this study, the frequency of hashtags used in CDC tweets was also analyzed. Twitter users can search a particular hashtag to follow an entire conversation revolving around that hashtag's topic. The CDC used hashtags often during campaigns or while live tweeting during events. Live tweeting occurs when a Twitter user watches or attends an event or other forms of entertainment and discusses the topics of the event throughout their tweets. Live tweets are often followed by a hashtag so users can follow an event's feed.

The hashtag used most often was "\#NCBDDD_10years" (17.5\%), including tweets with minor typos in the hashtag. As previously mentioned, NCBDDD stands for the National Center on Birth Defects and Developmental Disabilities, which is a center within the CDC. The NCBDDD celebrated 10 years of service in 2011 and centered an entire Twitter campaign on this notion. "\#VitalSigns" was used 3 percent of the time, 
while "\#SAM 2011" was used 1.1 percent of the time. SAM2011 stands for STD Awareness Month and was often associated with STD screening centers. The remainder of the hashtags was used less than 1 percent of the time. In totality, 61 percent of the tweets did not include any hashtag.

As shown in Table 5, there were three significant peaks in tweeting during April (28.8\%), March (21.2\%), and June (19.2\%). These peaks were often associated with the live tweeting campaigns during CDC events. These events are also associated with the high frequency of "NCBDDD" and "STDs and sex" topic-related tweets within the Twitter sample during certain months.

Table 5: Frequency by Month in @CDCgov Tweets

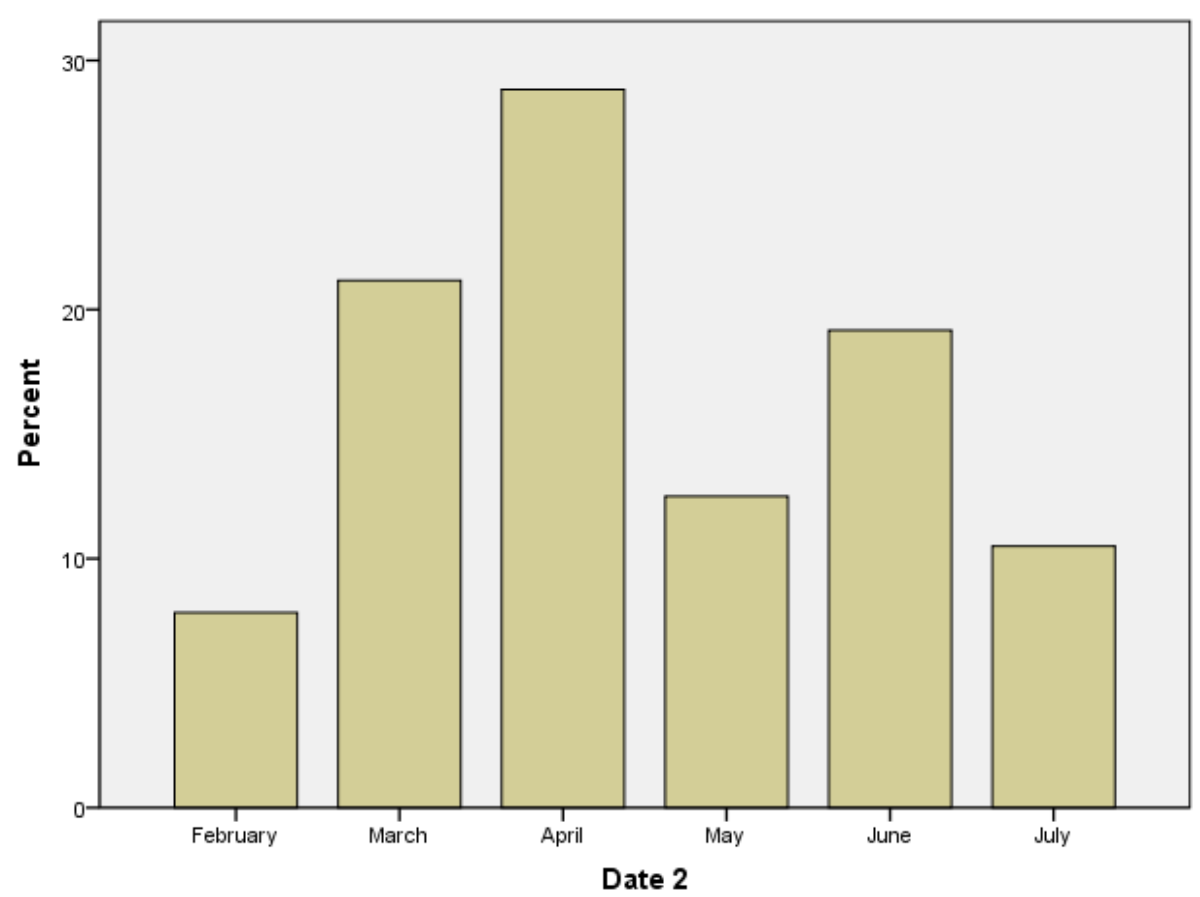


RQ2b: What topics are discussed in the CDC's social media release (i.e., Vital Signs)?

Because the CDC's Vital Signs releases have a set topic to be discussed each month, the health topics (agendas) were already known. Again, these topics included Cardiovascular Disease in February, Healthcare-Associated Infections in March, Teen Pregnancy in April, Asthma in May, Food Safety in June, and Cancer in July. When distributed into the health categories, Vital Signs releases discussed Specific Diseases/Disorders/Disabilities most often (50\%), and Family Health, Food Health, and Healthcare-Associated Infections equally (16.7\%, respectively).

\section{RQ3: What topics are discussed in the CDC's primary traditional media tactics during the same period?}

The CDC's traditional media tactics $(\mathrm{N}=52)$ were divided between press releases $(\mathrm{N}=37)$ and media advisories $(\mathrm{N}=15)$. Between these two groups, Specific

Diseases/Disorders/Disabilities was discussed most often (13 times), followed by Environmental Health, Disease Prevention, and Public Health Resources/Data.

\section{RQ3a: What topics are discussed in the CDC's press releases?}

The most discussed topic in the CDC's press releases was Specific Diseases/Disorders/Disabilities (24.3\%). Public Health Resources/Data, Disease Prevention, and Injury Prevention were all discussed 13.5 percent of the time, as seen

in Table 6 below. Within the non-collapsed categories, Healthcare-Associated Infections (10.8\%) and CDC Grand Rounds public health topics (10.8\%) had the highest 
distribution. The CDC Grand Rounds is a webcast on varying public health topics. Press releases also often discussed cancer (8.1\%). The remainder of the non-collapsed topics was discussed less than 6 percent of the time.

The month of March saw the most press releases (24.3\%), distributing 9 releases, while April and May each distributed 7 press releases (18.9\%). The remainder of CDC press releases was distributed one to two times a day.

Table 6: Frequency of Health Topics in Press Releases

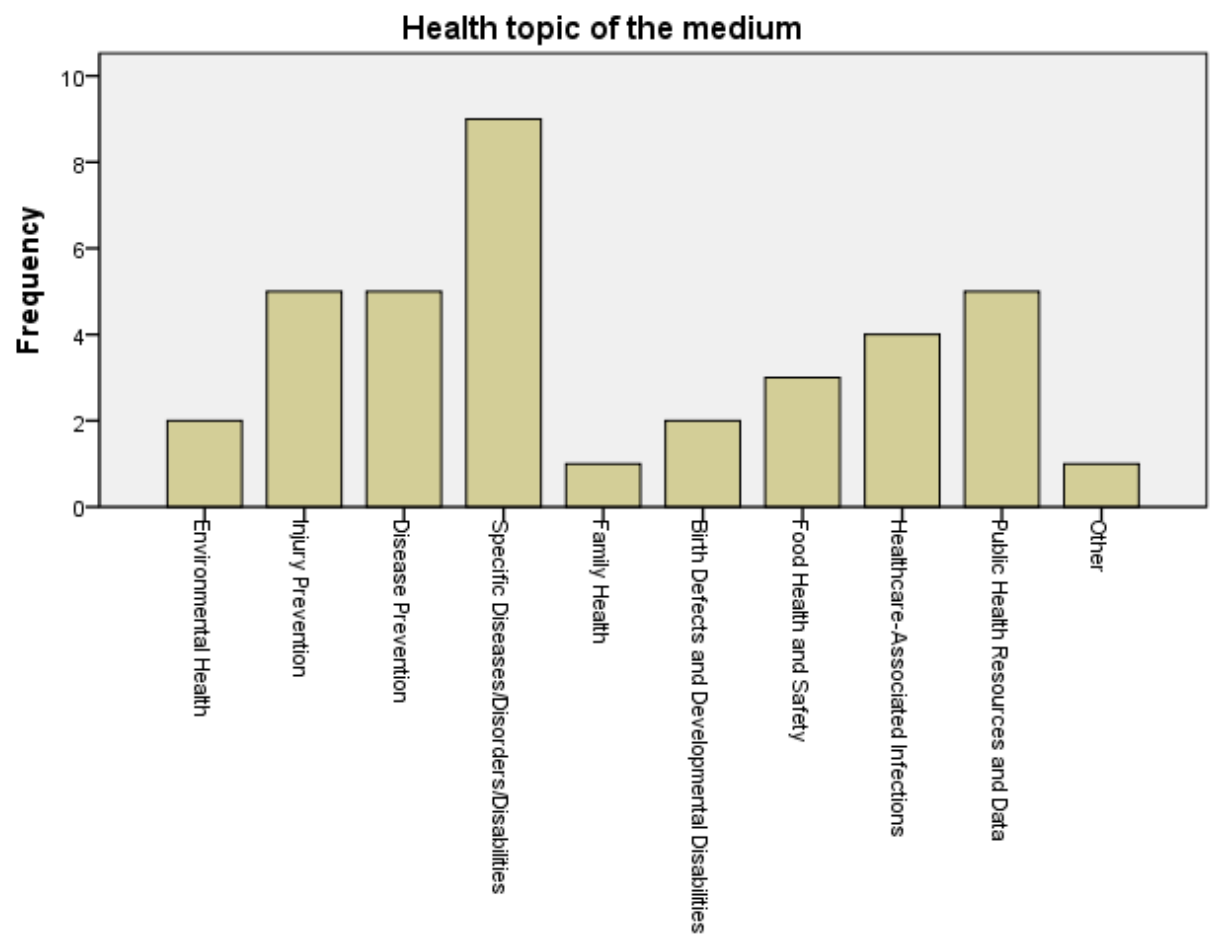

RQ3b: What topics are discussed in the CDC's media advisories?

The top three most discussed topics in the CDC's media advisories were Specific Diseases/Disorders/Disabilities (26.7\%), Injury Prevention (20\%), and Disease Prevention (13.3\%), as seen in Table 7 below. The remainder of the media advisories' health topics was mentioned only once (6.7\%). Within the non-collapsed health categories, immunizations and vaccines were discussed most often (13.3\%), while the 
remainder of the health topics was discussed only once (6.7\%). The months of February and June distributed the most media advisories (26.7\% respectively; 4 advisories per month). All other months distributed between 1 and 2 media advisories.

Table 7: Frequency of Health Topics in CDC Media Advisories

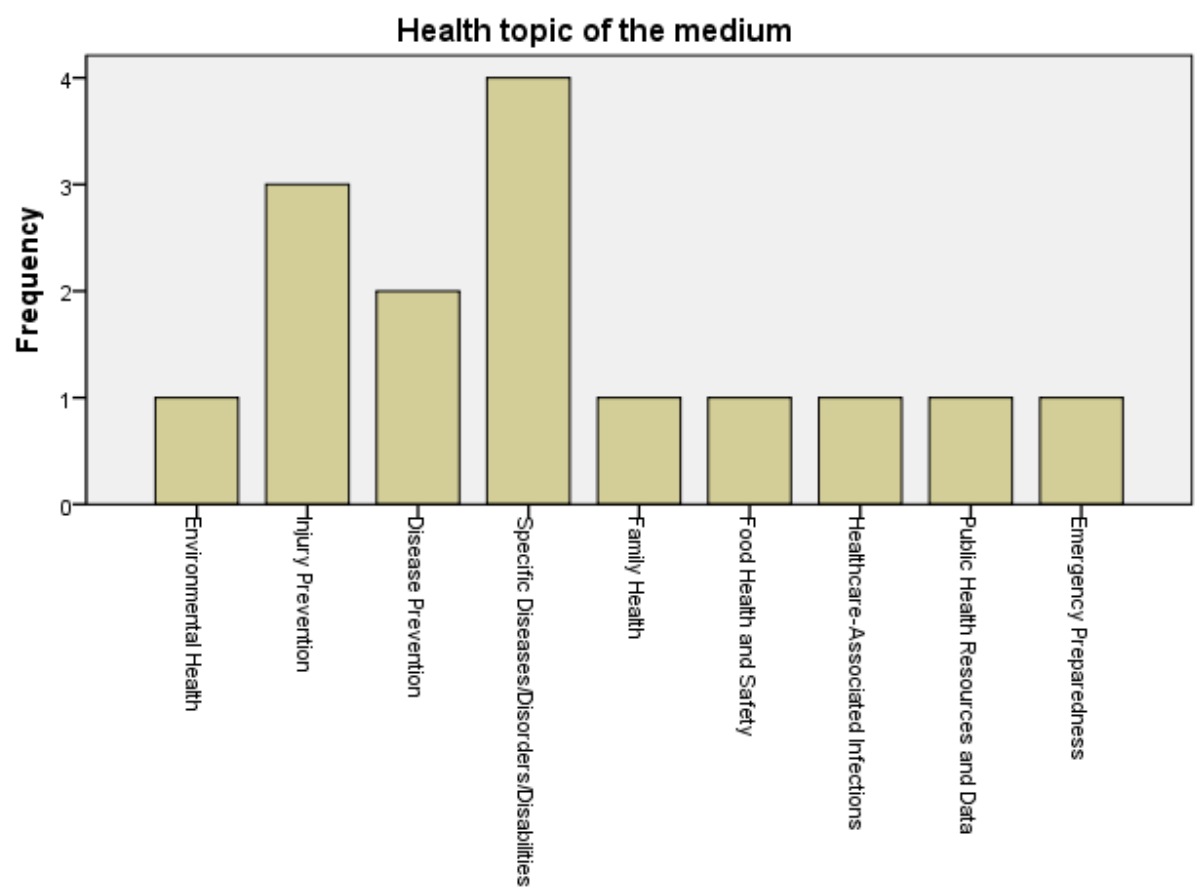

RQ4: Is there an association between the CDC's social media and traditional media topics?

There were a total of 658 messages in the entire CDC sample. A nonparametric correlation using Spearman's rho was conducted to discover correlations between CDC health topics and CDC mediums. Again, because there were numerous cells with counts of fewer than 5 , and more importantly in this study, with cells counts of 0 , the chi square test was not a scientifically robust method of analysis. Therefore, similar to other studies that explore media agenda building (Ragas, 2012), Spearman's rho, which uses ordinal ranks to measure the strength of relationships, was employed to explore 
associations between the CDC mediums. Table 8 represents the overall frequencies of health topics in all CDC mediums (i.e. social and traditional media).

Table 8: Crosstabulation of CDC Mediums by Health Topic

\begin{tabular}{|c|c|c|c|c|c|}
\hline \multirow[b]{2}{*}{ Health Topic } & \multicolumn{4}{|c|}{ Medium } & \multirow[b]{2}{*}{ Total } \\
\hline & Tweets & $\begin{array}{l}\text { Vital } \\
\text { Signs } \\
\end{array}$ & $\begin{array}{c}\text { Press } \\
\text { releases }\end{array}$ & $\begin{array}{c}\text { Media } \\
\text { advisories }\end{array}$ & \\
\hline Environmental Health & 31 & 0 & 2 & 1 & $5.2 \%(34)$ \\
\hline Injury Prevention & 36 & 0 & 5 & 3 & $6.7 \%(44)$ \\
\hline Disease Prevention & 43 & 0 & 5 & 2 & $7.6 \%(50)$ \\
\hline Specific Diseases/Disorders/Disabilities & 172 & 3 & 9 & 4 & $28.6 \%(188)$ \\
\hline Family Health & 31 & 1 & 1 & 1 & $5.2 \%(34)$ \\
\hline CDC Twitter Promotion & 61 & 0 & 0 & 0 & $9.3 \%(61)$ \\
\hline $\begin{array}{l}\text { Birth Defects and Developmental } \\
\text { Disabilities }\end{array}$ & 128 & 0 & 2 & 0 & $19.8 \%(130)$ \\
\hline Food Health and Safety & 31 & 1 & 3 & 1 & $5.5 \%(36)$ \\
\hline Healthcare-Associated Infections & 7 & 1 & 4 & 1 & $2 \%(13)$ \\
\hline Public Health Resources/Data & 29 & 0 & 5 & 1 & $5.3 \%(35)$ \\
\hline Emergency Preparedness & 6 & 0 & 0 & 1 & $1.1 \%(7)$ \\
\hline Other & 24 & 0 & 1 & 0 & $3.8 \%(25)$ \\
\hline News & 1 & 0 & 0 & 0 & $0.2 \%(1)$ \\
\hline Total & $91.2 \%(600)$ & $.9 \%(6)$ & $5.6 \%(37)$ & $2.3 \%(15)$ & $N=658$ \\
\hline
\end{tabular}

There were no significant associations among all CDC mediums $(\mathrm{N}=658), \mathrm{r}=$ $.035, p=.372$. Between CDC traditional media (i.e., press releases and media advisories), no significant association was found: $(\mathrm{N}=52), r=-.093, p=.512$. Between CDC social media (i.e., Twitter and Vital Signs), again, there was no correlation: $(\mathrm{N}=606), \mathrm{r}=.014, \mathrm{p}=.740$. Twitter and press releases, and Twitter and media advisories gave similar results: $(\mathrm{N}=637), \mathrm{r}=-.014, \mathrm{p}=.718$, and $(\mathrm{N}=615), \mathrm{r}=-.054, \mathrm{p}=$ .179, respectively. Lastly, between Vital Signs and press releases, and Vital Signs and 
media advisories, no significant association was found: $(\mathrm{N}=43), \mathrm{r}=-.080, \mathrm{p}=.612$, and $(\mathrm{N}=21), \mathrm{r}=-.240, \mathrm{p}=.295$

Additionally, to discover possible patterns in the timelines between these media and their topics, the researcher examined the dates of CDC health topics qualitatively. There did not seem to be any significant pattern or connection between the month in which topics were dominant and where they were disseminated. Specific Diseases/Disorders/Disabilities was the most common topic amongst all CDC mediums (44.6\%) in February 2011. However, March saw an increase from the previous month in Birth Defects and Developmental Disabilities (25.9\%), but this was only seen in tweets and press releases. March was also the second-highest distributor of CDC messages. Healthcare-Associated Infections was discussed by all mediums in March (6.5\%). The month of April saw the highest activity overall. Again, Birth Defects and Developmental Disabilities saw the highest use (36.3\%), but the majority of these messages were from Twitter. Family Health messaging was commonly distributed amongst all mediums in April (4.9\%). Specific Diseases/Disorders/Disabilities was consistently high in May, June, and July (41.2\%, 44\%, 22.5\%, respectively). However, Injury Prevention was consistently used in 3 out of 4 CDC mediums in May and June $(8.2 \%$ and $7.2 \%$, respectively).

RQ5: Are these health topics appearing in national media (i.e., Associated Press) during the study?

The AP sample included a total of 153 articles. From this sample, Specific Diseases/Disorders/Disabilities was the most discussed topic (22.9\%), followed by Food 
Health and Safety (19\%), as indicated in Table 9. From the AP stories emerged a new topic category: News (19\%). Again, this category was created for articles in which the health topic at hand was not actually the main topic of the story.

Table 9: Frequency of Health Topics in AP Articles

\begin{tabular}{|l|l|}
\hline Health Topic & Frequency \\
\hline Environmental Health & $11.1 \%(17)$ \\
Injury Prevention & $7.8 \%(12)$ \\
Disease Prevention & $11.1 \%(17)$ \\
Specific Diseases/Disorders/Disabilities & $22.9 \%(35)$ \\
Family Health & $3.3 \%(5)$ \\
Birth Defects and Developmental Disabilities & $0.7 \%(1)$ \\
Food Health and Safety & $19.0 \%(29)$ \\
Healthcare-Associated Infections & $1.3 \%(2)$ \\
Public Health Resources and Data & $2.6 \%(4)$ \\
Emergency Preparedness & $1.3 \%(2)$ \\
News & $19.0 \%(29)$ \\
Total & $\mathrm{N}=153$ \\
\hline
\end{tabular}

RQ5a: Are the social media topics appearing in these Associated Press stories?

There were a total of 759 messages in the $A P(N=153)$ and $C D C$ social media ( $\mathrm{N}=606)$ sample. The CDC's social media and AP topics most often discussed Specific Diseases/Disorders/Disabilities (27.7\%), Birth Defects and Developmental Disabilities (17\%), Food Health and Safety (8\%). To compare, within the CDC's social media topics, Specific Diseases/Disorders/Disabilities, Birth Defects and Developmental Disabilities, and Injury Prevention were discussed most often. 


\section{RQ5b: Are the traditional media topics appearing in these Associated Press}

\section{stories?}

There were a total of 205 messages in the AP $(N=153)$ and CDC traditional media sample $(\mathrm{N}=52)$. Similar to $\mathrm{RQ5a}$, between the three mediums, Specific Diseases/Disorders/Disabilities/STDs (23.4\%) was the most discussed topic, which is followed by Food Health and Safety (16.1\%), and Disease Prevention (11.7\%), as seen in Table 10. Again, the News category is specific only to AP stories. To compare, within the CDC's traditional media topics, Specific Diseases/Disorders/Disabilities, Environmental Health, Disease Prevention, and Public Health Resources/Data were discussed most often.

Table 10: Crosstabulation of Health Topic in CDC Traditional Media and the AP

\begin{tabular}{|c|c|c|c|c|}
\hline \multirow[b]{2}{*}{ Health Topic } & \multicolumn{3}{|c|}{ Medium } & \multirow[b]{2}{*}{ Total } \\
\hline & $\begin{array}{c}\text { Press } \\
\text { release } \\
\end{array}$ & $\begin{array}{c}\text { Media } \\
\text { advisory }\end{array}$ & AP story & \\
\hline Environmental Health & 2 & 1 & 17 & $9.8 \%(20)$ \\
\hline Injury Prevention & 5 & 3 & 12 & $9.8 \%(20)$ \\
\hline Disease Prevention & 5 & 2 & 17 & $11.7 \%(24)$ \\
\hline Specific Diseases/Disorders/Disabilities & 9 & 4 & 35 & $23.4 \%(48)$ \\
\hline Family Health & 1 & 1 & 5 & $3.4 \%(7)$ \\
\hline Birth Defects and Developmental Disabilities & 2 & 0 & 1 & $1.5 \%(3)$ \\
\hline Food Health and Safety & 3 & 1 & 29 & $16.1 \%(33)$ \\
\hline Healthcare-Associated Infections & 4 & 1 & 2 & $3.4 \%(7)$ \\
\hline Public Health Resources and Data & 5 & 1 & 4 & $4.9 \%(10)$ \\
\hline Emergency Preparedness & 0 & 1 & 2 & $1.5 \%(3)$ \\
\hline Other & 1 & 0 & 0 & $0.5 \%(1)$ \\
\hline News & 0 & 0 & 29 & $14.1 \%(29)$ \\
\hline Total & 37 & 15 & 153 & $\mathrm{~N}=205$ \\
\hline
\end{tabular}


RQ6: Is there an association between the CDC's media topics and AP topics during the study?

The content analysis did discover agenda-building associations between the health topics discussed within the CDC's social and traditional media tactics and the AP. Using Spearman's rho, a nonparametric correlation was conducted to determine the correlation between all CDC mediums and the AP.

Specifically, the test found that between the CDC's Twitter account, @CDCgov, and the AP, as shown in Table 11, there was an association: $(\mathrm{N}=753), r=.150, p<$ .001. However, the test found no significant association between Vital Signs issues and the AP: $(\mathrm{N}=159), r=.017, \mathrm{p}=.832$.

Table 11: Correlation between CDC Tweets \& the AP

\begin{tabular}{|lll|r|r|}
\hline & & & Medium & Health topic \\
\hline Spearman's & Medium & Correlation Coefficient & 1.000 & $.150^{* *}$ \\
rho & & Sig. (2-tailed) & .000 \\
& & $\mathrm{~N}$ & 753 & 753 \\
\cline { 2 - 5 } & Health topic & Correlation Coefficient & $.150^{* *}$ & 1.000 \\
& & Sig. (2-tailed) & .000 &. \\
& $\mathrm{~N}$ & 753 & 753 \\
\hline
\end{tabular}

**. Correlation is significant at the 0.01 level (2-tailed).

Table 12: Correlation between CDC Press Releases \& the AP

\begin{tabular}{|c|c|c|c|c|}
\hline & & & Medium & Health topic \\
\hline \multirow[t]{6}{*}{ Spearman's rho } & \multirow[t]{3}{*}{ Medium } & Correlation Coefficient & 1.000 & $.147^{*}$ \\
\hline & & Sig. (2-tailed) & & .043 \\
\hline & & $\mathrm{N}$ & 190 & 190 \\
\hline & \multirow[t]{3}{*}{ Health topic } & Correlation Coefficient & $.147^{*}$ & 1.000 \\
\hline & & Sig. (2-tailed) & .043 & \\
\hline & & $\mathrm{N}$ & 190 & 190 \\
\hline
\end{tabular}

*. Correlation is significant at the 0.05 level (2-tailed). 
When testing for associations between the CDC's press releases and the AP, as shown in Table 12, another significant association was found: $(\mathrm{N}=190), \mathrm{r}=.147, \mathrm{p}=$ .043. However, there was no association between the CDC's media advisories and the AP: $(\mathrm{N}=168), \mathrm{r}=.112, \mathrm{p}=.149$.

To discover possible patterns in the timelines between these media, the researcher examined the date of all topics qualitatively. In February, two category topics were discussed: Specific Diseases/Disorders/Disabilities (41.3\%) across all mediums and Disease Prevention (16\%) in 4 of the 5 mediums, including the AP. March saw the third-highest distribution of messages (157 total) and similarly ranked Specific Diseases/Disorders/Disabilities high among discussed topics (17.8\%). However, Healthcare-Associated Infections saw messaging distribution among all mediums. April was the highest distributor of messages overall (203 total). Birth Defects and Developmental Disabilities was discussed most often (32.5\%), but only in tweets. Therefore, Specific Diseases/Disorders/Disabilities was discussed most often (17.2\%). Specific Diseases/Disorders/Disabilities was again the most discussed amongst most CDC mediums and the AP in May, June, and July (38.1\%, 37.3\%, and 24.2\%, respectively). May also saw continued discussion of Injury Prevention in 4 out of the 5 mediums (8.6\%). June and July saw consistent discussion of Food Health and Safety in most CDC mediums and the AP (17.1\% and $13.2 \%$, respectively). In August, only AP articles were sampled to adjust for the time lag in the news media.

The most discussed topics in the AP this month were Specific Diseases/Disorders/Disabilities and Food Health and Safety (both at 36.4\%). Because 
these topics were highly discussed in the two previous months by CDC media, this suggests a possible agenda-building lag effect between the CDC and the AP. 


\section{Discussion}

CDC Health Topics and Campaigns.

Research questions 2-4 examined the most discussed health topics within the CDC's social and traditional media tactics. Because the category of Specific Diseases/Disorders/Disabilities included a large array of health topics, this category was the most discussed topic in all CDC mediums and during most months in the sample. But, each CDC medium varied in the subsequent topics that were commonly discussed and some CDC mediums were influenced by large campaigns. It appeared as though the CDC's traditional media did not often emphasize a single campaign of key messages. The CDC's Twitter content did emphasize campaigns in this sample, such as the NCBDDD campaign and the Top Global Public Health Achievements in First Decade of 21 st Century campaign. Vital Signs could also be defined as its own campaign amongst all CDC mediums, as it does have a set of key messages seen in several CDC mediums.

A campaign that had a significant impact on the Twitter agenda was the NCBDDD's 10-year anniversary, highlighting health achievements in birth defects, child development, blood disorders, and disability. This campaign accounts for 21.7 percent of the CDC's tweets and 17.5 percent of its hashtags. However, these campaign topics in large were not seen in other CDC media. Press releases did highlight risk behaviors associated with birth defects twice. CDC Twitter Promotion was also a largely discussed topic. Again, this category included prompts to complete Twitter satisfaction surveys, enter contests, watch videos or other social media promotion, and general Twitter 
conversation. This is to be expected on a social networking forum, as it promotes engagement with CDC Twitter followers.

The CDC promoted a similar campaign in May 2011: the Top Global Public Health Achievements in First Decade of 21st Century. This campaign attempted a more strategic messaging approach, including a press release and Twitter content about these health topics. This campaign highlighted topics that have enhanced public health over the past decade, such as immunizations, control of infectious diseases, family planning, safer and healthier foods, and tobacco control. Again, these topics can be observed in the non-collapsed health category list in the previous section or in Appendix E.

Due to this lack of streamlined messaging or agenda across CDC mediums, no associations were found between these CDC mediums. This suggests that the CDC may not be as strategic in their messaging as the interviewees suggested. The decentralized organization of the CDC's communications staff may influence this lack of successful strategic messaging and dissemination across the agency. Because each CIO within the CDC maintains its own campaigns, objectives, target audiences, tactics, and reach, it may be difficult to promote a streamlined campaign that receives high media and public attention. In addition, this variation in messaging and staff may result in varied levels of content quality. For example, one CIO may have one person or team solely dedicated to social media updates and strategy, which means this $\mathrm{CIO}$ has the time to ensure that messages are strategic. On the other hand, another $\mathrm{ClO}$ may have restricted staff, whose responsibilities include other tactics such as traditional media 
messaging, events, and speech writing. This leaves communications staff in that $\mathrm{CIO}$ with less time and fewer resources to dedicate to a single media tactic.

\section{Agenda-Building Associations.}

This study discovered two important agenda-building associations between the CDC's Twitter messaging and the AP, and between CDC press release messaging and the AP. This suggests the growing importance of social media messaging as well as the lingering effectiveness of traditional releases as public relations tactics. These findings parallel past research that has shown more than 80 percent of the wire stories on health used sources such as official proceedings, press releases, and press conferences (Cho, 2006). Despite this association, the personal interviews did not inform or suggest this result. In fact, interview participants did not emphasize the importance of press releases in message dissemination. One respondent explained that her office at the CDC did not rely on press releases and instead maintained personal contacts with media members, the contents of which were, of course, unknown for this study.

However, the interviewees did emphasize mainstream media pick-up through the social networking website Twitter, which was indeed supported by this study. This study was originally set to analyze the CDC's blog messaging. However, due to the large emphasis of social networking websites at the CDC by interview participants, Twitter was instead selected to analyze. The interview data informed the researcher to concentrate on Twitter, which led to another statistically significant association between the CDC's Twitter content and AP articles. 
This finding suggests that in addition to traditional public relations tactics, social media are, in fact, becoming effective in successful message dissemination and subsequent media pick-up. Not only that, but this finding also links to the public relations "e-release," HARO [Help A Reporter Out], which has since moved its PR messaging requests from email to Twitter. As previously stated, the interview results greatly informed this link to Twitter. In particular, an interviewee's story about launching a "zombie apocalypse" blog post was telling; it was not until she tweeted the blog post that Fox News called her to inquire about the post and see if the CDC had been hacked. Twitter is providing essential connections to a wide audience that press releases alone cannot provide.

Although Twitter was found to be effective in garnering media placement, the researcher did have difficulties interpreting the health topic of some of tweets in the sample. For the everyday Twitter user who follows @CDCgov, some of the content and health jargon may be confusing and deter them from following other CDC social media content. The interview results did suggest that CDC messaging often target professional audiences such as public health practitioners and healthcare providers, in addition to the general public and the media. The CDC should consider refining the wording of health messages when using popular social networking sites prior to sending them. Doing so could help ensure the content is understandable by the wide array of audiences who use social media today.

The interview results also suggested that the CDC was widely monitoring their media efforts and campaigns using multiple tools and programs. The category of CDC 
Twitter Promotion attested to this interview result, with a large number of tweets in this category representing Twitter survey promotion. The content of these tweets suggested that the survey aimed to track user sentiments and satisfaction with @CDCgov's messaging and content. Survey tweets were sent in pairs, with the first tweet asking users to take the survey, and the next suggesting users take the survey on a home computer for usability purposes.

Vital Signs did not seem to have a significant effect on any other medium in the sample. But, this may be due to the target audience and small sample size. As detailed in the personal interview results, Vital Signs releases do not specifically target the media. The release targets the general consumer, public health practitioners, and healthcare providers. Although targeting the media would in turn target the general consumer, it does not seem that this campaign is trying to do so.

After qualitatively looking at the messages sent over the timeline of the sample and by which medium, there were no obvious connections between the month a message was disseminated by the CDC and the time it was placed in the AP. However, there were suggested agenda-building effects in the month of August between the AP and the CDC media messaging on Food Health and Safety. This health category was the second-most discussed topic within the AP. In addition, within only the CDC mediums, the months of March and April saw some consistency in HealthcareAssociated Infections and Family Health messaging across all mediums. But this was still a small percentage of the overall distribution.

The results of this study found no correlation between the CDC's social and 
traditional media health topics, which suggest there is not a significant strategic messaging plan in place. This result suggests that the CDC should consider reevaluating their strategic messaging plans to better disseminate messaging across all CDC mediums to achieve higher saturation and salience. Because both press releases and tweets were found to be effective in garnering media placement, a more strategic and integrated approach should be considered to ensure CDC repetition of key messages across media and audiences. 


\section{Conclusion}

This thesis has attempted to discover strategic coordination of messaging across a large federal health organization and any agenda-building associations between it and the AP, which represents the national mainstream media. This study found important connections between both social and traditional media tactics in public relations that have the potential to inform public relations practitioners' media strategy today. However, the study did have notable limitations and points to numerous future research opportunities.

\section{Limitations}

Because this study examined the social and traditional media messages of only one national health organization and one international news wire service, during one specific timeframe, the findings of this study cannot be generalized to all health organizations, national media, or other time periods. In addition, this study only explored agendas in terms of occurrence of media topics. Without looking at agenda-setting level two, inferences about messaging frames cannot be determined.

Due to the graduate deadlines involved with this study, it was difficult to ensure the method was exhaustive. Because of these restrictions, the researcher was unable to extend the time frame longer than 6 months, as the sample size would not have been manageable. In addition, despite repeated attempts to broaden the pool, there were a limited number of interview participants in this study. Therefore, additional opinions regarding CDC message strategies and effectiveness may not have been discovered. This provided the study with a small level of saturation in the qualitative approach. In 
addition, the researcher was unable to reach a media relations professional at the CDC. The results of this interview would have additionally added to the context of the agency's agenda-building efforts in the press release and media advisory results.

Lastly, the intercoder reliability measure used in the content analysis could have been more rigorously tested by using a measure such as Holsti's formula, which accounts for random agreement. However, because health categories were not determined until after the content analysis was completed, performing a more rigorous test was not possible.

\section{Future Research}

Future research should consider analyzing media messages in health organizations using agenda-setting level two. This research may discover not only how health topics are being discussed, but also help to learn how they are being used to prime audiences' cognitive interpretations of them. Future research should also consider sampling a larger variety of health organizations across the U.S., as well as a broader sample of national U.S. media organizations to make possible associations of Twitter and press release agenda-building more generalizable. Also, by examining more social media health communities, a wider perspective of strategic social media messaging will emerge.

This study did not outline what CDC professionals constitute as a "campaign." Future studies should seek to define a clear understanding of what a campaign includes, as this will allow researchers to better measure a campaign's strategy and 
results. In addition, this study's statistical analysis only determined possible two-way correlations between mediums. Therefore, future research should analyze the influence that mainstream news pegs may have on the agenda's of health organization, in addition to the reverse.

Future research should also consider surveying national media journalists to discover how and to what extent they utilize social networking websites such as Twitter, in addition to social media releases, traditional press releases, media advisories, and personal contact to gain health-related news leads. With such a plethora of options, it could be that a few of these previously relied upon methods could fall by the wayside. This research would expand the conversation to help media relations professionals communicate more efficiently with media members. Lastly, this study provides a model for future agenda building research of this nature.

\section{Implications}

The results of this study fill a gap in research on the effectiveness and salience of social and traditional media health messaging and may be used both practically and academically. Practically, this study is relevant to public relations practitioners practicing in all fields because it informs them of possible trends in media relations and campaign messaging salience across several PR tactics. The results of this study also suggest that practitioners should consider a strategic messaging approach, which may allow for more effective campaigns and key messaging. Academically, this study reinforced previous findings of effective health communication techniques using social media tactics (Buis, 2009; Chou, et al., 2009; Pew Research Center, 2009; Avery, et al., 2010). 
These studies have similarly suggested the importance of social media in public relations and health messaging, and to the general public. The results of this study will enhance future research of this nature and serve as a starting point for additional agenda setting and agenda building research in this area. 


\section{References}

Article World. Agenda setting theory. Retrieved from http://www.articleworld.org/index.php/Agenda setting theory.

Austin, E., \& Pinkleton, B. (2006). Strategic public relations management. (2nd ed., pp. 77-78). Mahwah, NJ: Lawrence Erlbaum Associates.

Avery, E.J., Lariscy, R.A., Amador, E., Ickowitz, T., Primm, C., \& Taylor, A. (2010). Diffusion of social media among public relations practitioners in health departments across various community population sizes. Journal of Public Relations Research, 22(3), 336-358.

Briggs, M. (2010). Journalism next: A practical guide to digital reporting and publishing. CQ Press.

Briones, R. L., Kuch, B., Liu, B., \& Jin, Y. (2011). Keeping up with the digital age: How the American Red Cross uses social media to build relationships. Public Relations Review, 37(1), 37-43. doi:10.1016/j.pubrev.2010.12.006

Buis, L.R., \& Carpenter, S. (2009). Health and medical blog content and its relationships with blogger credentials and blog host. Health Communication, 24, 703-710.

Centers for Disease Control and Prevention, (2009). Social media campaigns. Retrieved from http://www.cdc.gov/SocialMedia/Campaigns/index.html.

Centers for Disease Control and Prevention: Office of the Associate Director for Communication, (2010a). The health communicator's social media toolkit. http://www.cdc.gov/healthcommunication/toolstemplates/socialmediatookit BM.p df.

Centers for Disease Control and Prevention, (2010b). Social media at the cdc: Blogs. Retrieved from http://www.cdc.gov/socialmedia/tools/blogs.html.

Centers for Disease Control and Prevention, (2011a). Vital Signs. Retrieved from http://www.cdc.gov/vitalsigns/aboutvitalsigns.html.

Centers for Disease Control and Prevention, (2011b). CDC social media tools, guidelines \& best practices. Retrieved from http://www.cdc.gov/SocialMedia/Tools/guidelines/. 
Centers for Disease Control and Prevention, (2011c). CDC organization. Retrieved from http://www.cdc.gov/about/organization/ClO.htm.

Centers for Disease Control and Prevention, (2011d). CDC.gov traffic. Retrieved from http://www.cdc.gov/metrics/cdcgov/cdcgov.html

Cho, Sooyoung. (2006). The power of public relations in media relations: A national survey of health pr practitioners. Journalism and Mass Communications Quarterly, 83(3), 563-580.

Chou, W.S., Hunt, Y.M., Beckjord, E.B., Moser, R.P., \& Hesse, B.W. (2009). Social media use in the United States: Implications for health communication. Journal of Medical Internet Research.

Christ, P. (2005). Internet technologies and trends transforming public relations. Journal of Website Promotion, 1(4), 1-14. doi:10.1300/J238v01n0402

Croft, A. (2008). Emergence of "new" media moves pr agencies in new directions: competitive pressure threatens agencies' livelihood. Public Relations Quarterly, 52(1), 16-20.

Curtin, P. A. (1999). Reevaluating public relations information subsidies: Market driven journalism and agenda-building theory and practice. Journal of Public Relations Research, 11(1), 53-90. Retrieved from EBSCOhost.

Denecke, K., \& Nejdl, W. (2009). How valuable is medical social media data? Content analysis of the medical web. Information Sciences, 179(12), 1870-1880. doi:10.1016/j.ins.2009.01.025

Department of Health and Human Services, (2010a). Ehealth data briefs: Blogs. Retrieved from http://www.cdc.gov/socialmedia/Data/Briefs/blogsdatbrief.pdf.

Department of Health and Human Services, (2010b). Ehealth data briefs: Social networking. Retrieved from http://www.cdc.gov/socialmedia/Data/Briefs/socialnetworksdatabrief.pdf.

Doss, G., \& Olivares, G. (2010). Social media for health communications. Proceedings of the National Conference on Health Communication, Media and Marketing, http://www.slideshare.net/glendoss/social-media-for-health-communications.

Edman, H. (2010). Twittering to the top: A content analysis of corporate tweets to measure organization-public relationships (Unpublished doctoral dissertation of master's thesis). Louisiana State University, Eunice, LA. 
Entman, R. (2000), 'Declaration of Independence: The Growth of the Media after the Cold War', in B. Nacos, R. Shapiro and P. Isernia (eds), Decision-Making in a Glass House, Lanham: Rowman \& Littlefield, 11-26.

Etter, M., Plotkowiak, T., \& Stanoevska-Slabeva, K. (2011). CSR-Communication in Twitter: The Annual Conference of the International Communication Association 2011. In Proceedings of the International Conference Association, 731.

Evans, M. (2010). Framing international conflicts: Media coverage of fighting in the Middle East. International Journal of Media \& Cultural Politics, 209-233. doi:10.1386/mcp.6.2.209_1

Eysenbach, G. (2001). What is e-health? J Med Internet Res. Retrieved from http://www.jmir.org/2001/2/e20/.

Eysenbach, G., \& Kohler C. (2003). What is the prevalence of health-related searches on the world wide web? Qualitative and quantitative analysis of search engine queries on the internet. Proceedings of the AMIA Annual Symposium, 225-229.

Fox, S. (2009, August 18). Social media's promise for public health. Retrieved from http://e-patients.net/archives/2009/08/social-medias-promise-for-publichealth.html.

Fox, S. (2011, May 12). The social life of health information, 2011. Pew Internet \& American Life Project. Retrieved from http://www.pewinternet.org/Reports/2011/Social-Life-of-Health-Info/Part1/Section-2.aspx.

Fox, S., \& Rainie, L. (2000). The online health care revolution. Retrieved April 5, 2011, from http://www.pewinternet.org/Reports/2000/The-Online-Health-Care$\underline{\text { Revolution.aspx }}$

Garcia-Retamero, R., \& Galesic, M. (2010). How to Reduce the Effect of Framing on Messages About Health. JGIM: Journal of General Internal Medicine, 25(12), 1323-1329. doi:10.1007/s11606-010-1484-9

Gilpin, D., Palazzolo, E. \& Brody, N. (2010). Socially mediated authenticity. Journal of Communication Management, 14(3), 258-278. DOI: $10.1106 / 13632541011064526$

Goodwin, L.D., \& Goodwin, W.L. (1984). Qualitative vs. quantitative research or qualitative and quantitative research? Nursing Research, 33(6), 378-380. 
Hawn, C. (2009). Take two aspirin and tweet me in the morning: How twitter, facebook, and other social media are reshaping health care. Health Affairs, 28(2), 361-368). DOI: 10.1377/hlthaff.28.2.361

Johnson, T.J. \& Kaye, B.K. (2004). Wag the blog: How reliance on traditional media and the Internet influence credibility perceptions of weblogs among blog users. Journalism \& Mass Communication Quarterly, 81, 622-642.

Kent, M. L. (2008). Critical analysis of blogging in public relations. Public Relations Review, 34(1), 32-40. doi:10.1016/j.pubrev.2007.12.001

Kiousis, S., Poescu, C., \& Mitrook, M. (2007). Understanding influence on corporate reputation: An examination of public relations efforts, media coverage, public opinion, and financial performance from an agenda-building and agenda-setting perspective. Journal of Public Relations Research, 19(2), 147-165.

Kitchen, P. J., \& Panopoulos, A. (2010). Online public relations: The adoption process and innovation challenge, a Greek example. Public Relations Review, 36(3), 222229. doi:10.1016/j.pubrev.2010.05.002

Kuzma, K. (2010). Agenda building in the blogosphere: A communication audit of blogging at beth israel deaconess medical center. Chapel Hill, ProQuest.

Lagu, T., Kaufman, E.J., Asch, D.A., \& Armstrong, K. (2007). Content of weblogs written by health professionals. Journal of General Internal Medicine, 23(10), 1642-1646.

Langosa, G. (2008). Blogs and big media: A comparative study of agendas. Retrieved from Dissertations and Theses database.

Lariscy, R. W., Avery, E. J., \& Sohn, Y. (2010). Heath journalists and three levels of public information: Issue and agenda disparities?. Journal of Public Relations Research, 22(2), 113-135.

Len-Rios, M., Hinnant, A., Park, S., Cameron, G.T., \& Frisby, C.M. (2009). Health news agenda building: Journalists' perceptions of the role of public relations. Journalism and Mass Communications Quarterly, 86(2), 315-331.

Madden, M., \& Zickuhr, K. 65\% of online adults use social networking sites. Pew Internet \& American Life Project, Aug. 26, 2011, http://www.pewinternet.org/Reports/2011/Social-Networking-Sites.aspx?src=prcheadline, accessed on August 29, 2011. 
Martinelli, D. K., \& Mucciarone, J. (2007). New deal public relations: A glimpse into fdr press secretary stephen earl'ys work. Public Relations Review, 33, 49-57.

McCarthy, C. (2011, February 25). Why social media gives your doctor an ulcer. Retrieved from http://news.cnet.com/8301-13577 3-20036107-36.html.

McCombs, M. (2005). A look at agenda-setting: Past, present and future. Journalism Studies, 6(4), 543-557. doi:10.1080/14616700500250438

McCombs, M. E., \& Shaw, D. L. (1972). The agenda-setting function of mass media. Public Opinion Quarterly, 36(2), 176-187. Retrieved from http://search.ebscohost.com.www.libproxy.wvu.edu/login.aspx?direct=true\&db=uf $\underline{\mathrm{h} \& \mathrm{AN}=5414703 \& \text { site }=\text { ehost-live. }}$.

Meraz, S. (2009). Is there an elite hold? Traditional media to social media agenda setting influence in blog networks. Journal of Computer-Mediated Communication, 682-707.

Miller, E.A., \& Pole, A. (2010). Diagnosis blog: Checking up on health blogs in the blogosphere. American Journal of Public Health, 100(8), 1514-1519.

Pew Research Center. (2009). New media index. Retrieved September 1, 2011, from http://www.journalism.org.

Pew Research Center. (2010, May 23). New media, old media: How blogs and social media agendas relate and differ from traditional press. Retrieved from http://pewresearch.org/pubs/1602/new-media-review-differences-from-traditionalpress.

Polack, E.P., \& Avtgis, T.A. (2011). Medical communication: Defining the discipline. Kendall Hunt.

Porter, L. V., Sweetser Trammell, K. D., Chung, D., \& Kim, E. (2007). Blog power: Examining the effects of practitioner blog use on power in public relations. Public Relations Review, 33(1), 92-95. doi:10.1016/j.pubrev.2006.11.018

Ragas, M. W. (2012). Issue and stakeholder intercandidate agenda setting among corporate information subsidies. Journalism \& Mass Communication Quarterly, 89(1), 91-111.

Riffe, D., Lacy, S., \& Fico, F. G. (2005). Analyzing media messages: Using quantitative content analysis in research. (2 ed., pp. 1-242). Mahwah, New Jersey: Lawrence Erlbaum Associates, Inc. 
Rubin, H. J., \& Rubin, I.S. (2005). Qualitative interviewing: The art of hearing data. $2^{\text {nd }}$ ed. Thousand Oaks, CA: Sage Publications.

Sharp, J. (2010, May 06). Social media in health care: Barriers and future trends. Retrieved from http://www.ihealthbeat.org/perspectives/2010/social-media-inhealth-care-barriers-and-future-trends.aspx.

Smith, C. (2010, August 22). Internet usage statistics: How we spend our time online (infographic). Retrieved from http://www.huffingtonpost.com/2010/06/22/internetusage-statistics n 620946.html.

Smith, R. (2007). Media depictions of health topics: Challenge and stigma formats. Journal of Health Communication, 12, 233-249.

Social media being adopted by patients, health care providers. (2010). PTinMotionmag, Retrieved from ptinmotionmag.org.

Sublet, V., Spring, C., \& Howard, J. (2011, March 4). Does the niosh science blog improve communication?. Retrieved from http://www.cdc.gov/niosh/blog/nsb030411 blog.html.

Sweetser, K. , \& Lariscy , R. W. (2008). Candidates make good friends: An analysis of candidates' uses of Facebook. International Journal of Strategic Communication, 2, 175-198 .

Sweetser, K. D., Porter, L. V., Soun Chung, D., \& Eunseong, K. (2008). Credibility and the use of blogs among professionals in the communication industry. Journalism \& Mass Communication Quarterly, 85(1), 169-185. Retrieved from EBSCOhost.

The Associated Press, (2011). About AP. Retrieved from http://www.ap.org/pages/about/about.html.

Thielst, C. (2007). Weblogs: A communication tool. Journal of Healthcare Management, 52(5), 287-289.

Turk, J. V. (1986). Public relations influence on the news. Newspaper Research Journal. 7(4), 15-27.

Twitter. (2012). What are hashtags ("\#" Symbols)?. Retrieved from https://support.twitter.com/articles/49309-what-are-hashtags-symbols.

Viswanath, K. (2008). Health communication. International encyclopedia of communication. Retrieved February 27, 2011, from 
http://www.communicationencyclopedia.com.www.libproxy.wvu.edu/subscriber/ui $\mathrm{d}=2241 /$ tocnode?query $=\% 22$ social + media $\% 22 \% 2 \mathrm{C}+$ health\&widen=1\&result nu mber $=2 \&$ from $=$ search\&id=g9781405131995 chunk g978140513199513 ss91\&t ype $=$ std \&fuzzy $=0 \&$ slop $=1$ \&authstatuscode $=200$.

Wallington, S.F., Blake, K., Taylor-Clark, K., \& Viswanath, K. (2010). Antecedents to agenda setting and framing in health news: An examination of priority, angle, source, and resource usage from a national survey of U.S. health reporters and editors. Journal of Health Communication, 15, 76-94.

Wallington, S.F., Blake, K., Taylor-Clark, K., \& Viswanath, K. (2009). Challenges in covering health disparities in local news media: An exploratory analysis assessing views of journalists. Journal of Community Health, 35.

Wallsten, K. (2007). Agenda setting and the blogosphere; an analysis of the relationship between mainstream media and political blogs. Review of Policy Research, 24(6), 567-587.

Waters R., Burnett, E., Lamm, A., \& Lucas, J. (2009). Engaging stakeholders through social networking: How nonprofit organizations are using facebook. Public Relations Review, 35, 102-106.

Waters, R., Tindall, N. \& Morton, T. (2010). Media catching and the journalist-public relations practitioner relationship: How social media are changing the practice of media relations. Journal of Public Relations Research, 22(3), 241-264. DOI: 10.1080/10627261003799202

Wise, K. (2010). Public relations and the visioning process in healthcare: Perspectives of US practitioners. Journal of Communication in Healthcare, 3(3-4), 258-265.

Zhou, S., \& Sloan, WM. D. (2009). Research methods in communication. Northport, AL: Vision Press.

Zickuhr, K. (2010, December 16). Generations online in 2010. Pew Internet \& American Life Project. Retrieved from http://pewresearch.org/pubs/1831/generationsonline-2010. 


\section{Appendix A: Interview Guide}

\section{Introduction/Welcome}

- Introduction of researcher

- Basic guidelines for the interview (i.e. Can share results of study, names can be redacted later)

- Allow participant introduction

Warm-up

Mod: "How long have you been employed at the CDC?"

Mod: "What is your main job function?"

Mod: "What functions does the CDC communications team perform overall?"

CDC Communications Plan

Mod: "Does the CDC communications team have a strategic communications plan?"

Mod: "If so, does this plan include objectives and messaging for both traditional and social media tactics?"

Mod: "What do you consider your main form of communication with the media?"

\section{Roles of CDC information subsidiaries}

Mod: "Does your does this plan include a list of key messages to be disseminated through your traditional tactics?"

Mod: "If not, how do you choose what issues to focus on for your traditional media?"

Mod: "In your experience, what traditional public relations tactic has been most influential in reaching the media?"

\section{Roles of social media}

Mod: "Does your team set key messages or topics that must be disseminated through social media? How do you determine these topics?"

Mod: "What audience do the CDC's social media content cater toward?" 
Mod: "What roles do you believe blogs and blog posts play in alerting the media of topics and issues, or the public, if any?"

Mod: "What role does your social media release, Vital Signs, play in alerting the media, or the public, if any?"

\section{CDC Organization}

Mod: "Do separate professionals write and disseminate the content for the CDC's social media than those who write and disseminate content for the CDC's traditional media?"

Mod: "Who updates your social networking outlets, such as Facebook and Twitter?"

Mod: "How do you determine these micro-messages?"

\section{CDC Measurement}

Mod: "Do you evaluate or seek to measure what seems to be most effective in media coverage?"

Mod: "If so, which tactics do you find most effective in reaching media outlets?"

Mod: "In your experience, has the mainstream media adapted to receiving information through the Internet, such as Vital Signs and blog posts?"

Mod: "Do you think media professionals have a preference for how they receive information from the $\mathrm{CDC}$ ?

\section{Attitudes and Perceptions}

Mod: "As a media professional, how do you see blogs influencing the nation's health agenda in the media world, if at all?"

Mod: "Do you find individuals or the media interacting with and responding to your social media tactics? Why do you think that is?"

Mod: "Are you active in social media (blogs, social networking, etc.)? If so, what functions do social media tools play in your daily life? If not, why? 


\section{Appendix B: Email Correspondence with Interviewees}

\section{From: Kristen Wishon \\ Sent: Monday, October 17, 2011 4:23 PM \\ Subject: Academic Interview Inquiry}

Dear Ms. Reynolds,

My name is Kristen Wishon and I'm a second year Journalism Master's student at West Virginia University. I'm currently working on my thesis about media coverage of health issues, and am asking for your assistance. My thesis focuses on how social media and traditional media have an intermediary effect, if at all, in health communication. I'm specifically looking at the Centers for Disease Control and Prevention's tactics because of your organization's prominence and health expertise. However, before I can conduct a content analysis, I am hoping to conduct interviews with 2-3 communication staff members at the CDC.

The purpose of the interviews is to learn what your staff deems the most successful media tactics. In addition, questions on how traditional media outlets and your audiences use your online resources will be asked. The identified tactics will then be selected for analysis. I am happy to share my study results with you once all data has been collected. In addition, if an individual does not want identifying information included in the final thesis draft, his or her identifying information will be redacted.

To help me move forward with this study, will you please recommend 2-3 of your communications contacts who have worked with social media or traditional media tactics at the CDC?

Thank you for your consideration and help. If you have questions about this project, please feel free to contact me at 304-741-5773 or my thesis chair, Dr. Diana Martinelli at 304-293-6561. I look forward to hearing from you.

Sincerely,

Kristen Wishon

107 Martin Hall

P.I. Reed School of Journalism

West Virginia University

Cell: 304-741-5773 
From: Kristen Wishon

Sent: Monday, December 19, 2011 12:41 PM

To: Silver, Margaret E. (CDC/OPHPR/OD)

Subject: Interview Follow-Up

Hi Maggie,

I hope you're doing well and beginning to enjoy the holiday season! I've been preparing my interview transcriptions for analysis and have a few follow-up questions for you. I realize this is a busy time of year, so please take your time.

1. What is your official job title that should be included in my analysis? Your signature says "Communications Office/Office of the Director," is this what I should include? Health Communication Specialist, Office of Public Health Preparedness and Response, Centers for Disease Control and Prevention (my office and CDC are optional you can leave both out or just keep CDC depending on your space))

2. For the Vital Signs campaign (I never received a response from anyone, which is no problem!), who actually determined the set topics? You mentioned your Director did, but it seems there are many director positions at the CDC. Could you clarify?

FORWARDING TO DIANE

3. In addition, with Vital Signs, I have decided to include it in my analysis. However, since the topics are already set every year, it seems unnecessary to do a content analysis on them. Would you be able to provide me with a list of the set Vital Signs topics per month? FORWARDING TO DIANE

4. You mentioned that each $\mathrm{ClO}$ with a social media profile must have a set social media plan and pre-cleared social media messages. Who actually approves these messages? Again, you mentioned the Associate Director of Communications does this task. However, does each $\mathrm{CIO}$ have their own ADC, or is this the same person for each communications office? The process may vary slightly, but according to CDC Social Media policy, each $\mathrm{ClO}$ should have a plan in place and clear their messages through the appropriate management. This means either their Associate Director for Communication or their Associate Director for Science and Communication. Every CIO has an ADC or ADCS and part of their role is to approve public messages. You can learn about social media at CDC here (there is also a section on Vital Signs).

I seem to be having some clarification issues with the Director and Associate Director positions and roles. But I do want to make sure I'm including correct information in my analysis. Each $\mathrm{ClO}$ has a Director and then Associate Directors for various offices (AD 
of Communication, $A D$ of Learning, $A D$ of Financial Resources, etc.) This varies slightly between the ClOs, but the concept of Associate Directors is consistent across CDC.

In charge of everyone is the director of CDC, Dr. Thomas Frieden. Here's a link to a CDC org chart, and attached is my Office's org chart, you'll see all of our AD's on the left hand side under our Deputy Director Lynn Austin. In the Office of Public Health Preparedness and Response (considered a $\mathrm{ClO}$ ) we have a Director (Ali Khan) and two Deputy Directors. Then we have an Office of the Director which includes the Communication Office, Learning Office, Policy Office, etc. These offices support the Divisions, of which there are four: Division on Emergency Operation, Division of Select Agents and Toxins, Division of State and Local Readiness, and Division of Strategic National Stockpile. You'll also notice on the right hand side of the org chart we have several advisors and liaisons. Hope that helps give you a clearer picture. Every $\mathrm{CIO}$ follows a similar break down: Director, Office of the Director, Divisions, Branches.

Thanks again for your assistance in this process and your insights have been very helpful.

Kristen

From: "Brodalski, Diane J. (CDC/OD/OADC) (CTR)"

Tuesday - December 20, 2011 2:08 PM

To: "Silver, Margaret E. (CDC/OPHPR/OD)"

CC: "Kristen.Wishon@mail.wvu.edu"

Subject: RE: Interview Follow-Up

The topics were determined by Dr. Frieden, the CDC Director and senior level leadership.

The Vital Signs topics:

\author{
Cancer \\ Obesity \\ Tobacco \\ Motor Vehicle Safety \\ HIV \\ Alcohol \\ Cardio vascular Disease \\ Healthcare associated infections \\ Teen Pregnancy \\ Asthma
}


Food Safety

Prescription Drug Overdose

Topic selection: A number of the Vital Signs topics are also Winnable Battles - defined as public health priorities that $\mathrm{CDC}$ and public health can make significant progress in a relatively short time. CDC's winnable battles are:

- Healthcare-associated infections

- HIV

- Motor vehicle injuries

- Obesity, nutrition and food safety

- Teen and unintended pregnancy

- Tobacco

Winnable battles address the leading causes of death and disability, are evidencebased interventions that exist and can be broadly implemented and CDC's intensive focus and efforts can have a significant impact in a short period of time. Additional information can be found on Winnable Battles at the following link:

http://www.cdc.gov/winnablebattles/

I will need to gather some additional information on the topic selection. Please note that a number of folks are on holiday leave so it may take some time to contact.

\section{Diane Brodalski}

Contractor, Northrop Grumman

From: "Schindelar, Jessica (CDC/OD/OADC)"

Tuesday - December 20, 2011 4:33 PM

To: Kristen Wishon

Subject: RE: Interview Follow-Up

Happy to provide some additional information. In response to your questions below:

1. You mentioned that the CDC is beginning to reach health care providers through some targeted physician networks. Could you expand on these networks? Are they a targeted social media network, or something a bit more professional?

CDC is working with a variety of targeted physician networks to reach healthcare providers, including both professional networks like the American Medical Association, Epocrates and Medscape, as well as targeted physicianonly social networks such as Sermo and QuantiaMD. Our full list of partners for healthcare provider outreach include: 
American Medical Association

Epocrates.com

Medscape

Microsoft HealthVault

Modern Medicine

Osmosis

QuantiaMD

Sermo

Up-to-Date

VeoMed

2. For CDC micro-messaging, it depends on the $\mathrm{CIO}$ as to who or how many people actually update these accounts. However, at the OD level, you mentioned it was a collaborative process because communicators are updating for all campaigns. Could you clarify this? Do different campaigns send pre-cleared tweets to your level to send out on the main CDC accounts, as well as their own?

Tweets for the main CDC accounts come from a variety of sources - typically when we send out any content from the main CDC profiles, it has been precleared and provided by a program at CDC. Because we sit in the OD, we don't technically "own" any content - we are reliant on the programs who are the scientific "owners" of the topic area (for example, the Office on Smoking and Health "owns" tobacco control and smoking content) to provide us with pre-cleared tweets. For CIOs that have their own profiles, they will usually send their content out on their channel first, and then we will retweet their messages on our main CDC profile. In some instances though, programs will send us pre-cleared tweets for the main CDC accounts, in addition to their own - a good example of this is for certain Vital Signs topics, where the program has their own Twitter profile, they'll develop messages for both their account and the main CDC accounts.

I hope this helps clarify those points - please let me know if I can provide any additional information or if you have additional questions.

Thanks!

Jessica Schindelar, MPH 


\section{Appendix C: Phone Interview Transcriptions}

\section{Jessica Schindelar \\ November 14, 2011 at 3:00 p.m., ended at 3:22 p.m.}

Schindelar: My area of expertise is in social media.

Moderator: How long have you been employed at the CDC and described your main job functions?

Schindelar: Sure, um, I've been working at CDC for the past $31 / 2$ years now. I work in our Office of the Associate Director of Communications on our Social Media Team and my primary role is to provide guidance, leadership, and expertise to different programs across the agency and how to incorporate social media into their overall communications campaigns. So I do a lot of consulting with a lot of different campaigns. Things like the Vital Signs campaign, and the Annual Seasonal Flu Vaccination Campaign. I'm working with the new Million Hearts campaign, which is, the goal is to reduce heart attack and stroke by 1 million over the next 5 years. So I kind of work on helping to develop social media tactics that support and complement the overall communications campaigns that are going on.

Moderator: Okay, does each department, division, and those things, do they have their own communication plan or team?

Schindelar: Yes. So the way that communications works across the agency is that we have a centralized office at the Office of the Director level, which is where my team sits. But then there are also communications offices within each of the national centers across the agency. So, the birth defects group has their own communications office, the Injury Center has their own communications office. So it's a very decentralized model on how we do communications from the agency. At OD level, my team manages the agency-wide social media channel. So, we're responsible for the CDC Facebook page, a couple of the agency-wide Twitter profiles. And then there's a variety of different pages and profiles that are managed at the different campaign and topic area.

Moderator: My next question for you is, you mentioned an overall communications plan, and so how do you guys set that plan? Do you all come together and set your objectives? How does that work?

Schindelar: Technically the way that it works, with the different campaign areas, is the different communications staff within that topic area kind of start with their objectives and who their audience is and who their trying to reach. And then they start thinking through their traditional communications strategy and then I will work with them to help identify social media tools that would help complement that strategy. So it really is set more at the program level as to what their objectives are for a specific campaign. 
Moderator: For you in particular, as you work with social media, do you work with the mainstream media at all to get media placement? If so, what would be your main form with communication with the media?

Schindelar: Um, within our social media group, we don't necessarily work with the mainstream media. Our Electronic Media and News Media teams are in the same organizational unit, but they're like a separate branch from us. So we have groups over there that do the traditional media outreach and then we do have a liaison from my team to that group who helps to integrate. So when there's a new press release or anything like that, we will send it out on our social media channels. But we don't work directly with the media at all on my team.

Moderator: For Vital Signs in particular, and the blogs, I'm getting the feeling that these are moderator on the different division and campaign levels. But who updates the blogs, who sets the key messages for the blog topics?

Schindelar: Um, it really depends on the different blogs. There are about 9 or 10 different blogs on a variety of different topics across the agency. So there is the Public Health Matters blog, which is the one that you probably saw. It was popular back in the spring when they did the Zombie Apocalypse post. That was managed by the Office of Public Preparedness and Response, and they have their communications staff actually write and post all those blogs. So really depends on who owns the blog. So the Injury Center has a blog for their Center Director and their communications staff does all the posting for those.

Moderator: Does the same go for the Vital Signs release?

Schindelar: The Vital Signs release is a little bit more of an agency-wide effort. The Vital Signs product is managed out of our Office of the Director level, and then the topics rotate each month, so they work with different programs to develop the key messages and all of that stuff. But the Vital Signs product, that is managed, um, at our level. Though, we have a staff member on my team that is dedicated to working with the programs each month to develop their social media strategy for that release.

Moderator: And so, you guys don't determine the topics for those releases?

Schindelar: No, those are actually set in there, um, each month has its own topic and there, so each year their going to go back and do an update on the topic. So those topics are set by month. So I think, coming up in December is HIV testing, and it's every December that will be the Vital Signs topics. So the topic stays the same from year to year.

Moderator: That's interesting. And so for you, with social media, since you're working with so many groups and campaigns, for the CDC social media, who does that generally cater toward when you're working on campaigns? 
Schindelar: We have a variety of different audiences that we're trying to reach. Obviously some of our mainstream channels like our Facebook page and our Twitter profiles are much more catered toward a general consumer audience. But we do have, we know that one of our big audiences for CDC communications products as a whole are public health professionals. So a lot of public health practitioners at the state and local level and at the federal level. So that's another big audience for us. Then I would say health care providers are our third kind of big audience that we try and hit. We use a little bit different tactics for some of the other, I mean Facebook fits general consumer versus we have some outreach that we're doing through some targeted physician networks to reach healthcare providers specifically.

Moderator: For Vital Signs, who would you say that's generally catering toward?

Schindelar: I think the way that that is set up is there are actually three key audiences for that. So there's the general consumer, each month they have kind of a breakdown of what we can do as an individual to help with the problem, what public health practitioners can do, um, and then I think the third...it depends on the topic I think, but there are some health care provider, um, focused in there. And then also policy makers are another key audience in there.

Moderator: For your micro-messages, such as on Facebook and Twitter, does a separate person facilitate those messages or is it a group effort?

Schindelar: From the actual posting perspective, we have two members of our team who are responsible for doing that. But the development of the content is, because we're posting content for everybody across the agency that is a very collaborative process. And we have a staff member who is kind of dedicated to coordinating all the content that is posted. So she does a lot of back and forth to get approval on messaging, and make sure the messages are right for the different channels, and um, she develops an editorial calendar every week that we kind of follow.

Moderator: For social media, as far as measurement and evaluation goes, how do you evaluate your social media tools, and your blogging, and all that stuff to see what is actually gaining attention in your audiences.

Schindelar: Um, we're using a couple of different things. I would say more from the metrics than measurement perspective. Um we're looking at the kind of trends in engagement, and followers so we're tracking those over time, we're tracking growth. We're also able to track traffic back to our website from our social media properties. So we're able to track things like click-throughs back from a Facebook page or a Twitter profile, we're looking at page views on our blogs, the numbers of comments that are coming in, those kind of engagement metrics. Um, we're doing a lot of, well not a lot of, we're moving kind of into using social media monitoring tools like Radian 6 to get a sense of where our messages are going once we release them. Um, and I know they use that pretty extensively for the Vital Signs campaign. They're definitely keeping an eye on that. And that tracks both social and traditional media, I believe. Um, so we're 
using that to kind of look at the traction of our messaging and then from an evaluation perspective it's a little bit newer for us. We're kind of exploring how we can best measure the impact of our social media messaging from a health perspective. That's definitely something we're working on trying to figure out. We've done some surveys and things like that to get a sense of who our users are and what they're doing with our information and if they are satisfied with what they're seeing on our profiles, and they're satisfied with how frequently we post and those kinds of things. I guess more audience sentiment and user satisfaction; um we're still trying to figure out how to measure that impact.

Moderator: I know you said you don't generally work with mainstream media outlets, or anything like that, but in your experience have you found that particular social media tactics have been more effective in reaching media?

Schindelar: Um, hm.

[pause]

Moderator: I have seen that Vital Signs has been picked up in a few spots. Like you said, the zombie apocalypse blog was picked up as well.

Schindelar: Yea, yea. It really just started as a blog post and it picked up traction and got the attention of the mainstream media. I really think it depends. I don't know if there's a magic bullet.

Moderator: On the topic?

Schindelar: Yeah.

Moderator: Because one of the things I'm going to look at after the interview occur, I'm going to content analyze specific mediums from the CDC. So I might choose to content analyze a blog or the Vital Signs reports. But, l'm trying to see what you think is the most influential overall.

Schindelar: I know that we do, kind of from a message dissemination perspective around Vital Signs; we do a lot of push around using Twitter to get messages out and get some of those key messages out that are related to that Vital Signs release. So I definitely think that that's one, and I know from our audience surveys that we probably have a little bit more of a media audience on our Twitter profiles than say, on our Facebook profiles.

Moderator: Oh that's interesting, okay.

Schindelar: It's definitely not a significant audience on our Twitter profile, but I know that there is an audience there that we don't have as much on our Facebook page. 
Moderator: Do you think that media professionals, and again I know that you don't work with them directly often, but do they have a preference on how they receive information from the CDC? Do they like receiving Vital Signs versus blog post information versus press release, do you know?

Schindelar: Um, I don't know.

Moderator: That's fine. Lastly, just a few more questions, personally do you read blogs, are you active in social networking, social media?

Schindelar: Yes, actually I would say probably most active in reading blogs and I use Twitter a lot.

Moderator: Okay, what blogs do you read?

Schindelar: Um, Huffington Post, some of the like, um, CNN health blog and NPR blog. And then some of Mashable and Techcrunch and some of the social media tech blogs.

Moderator: Important question, probably hard to answer actually. But as a media professional, how do you see social media, in general, influencing the nation's health agenda?

Schindelar: Influencing the health agenda?

Moderator: Mhm, in the media world, if at all. Do you see it influencing how your audiences are taking care of themselves?

Schindelar: From a kind of health communications perspective, I think that it's getting more attention now because of social media. I feel like the messages are out there, um, so much more now than they used to be. Before, you know, information was just sitting on our web site, and I think social media is allowing us to feed out health information into the social media spaces. In fact, I feel that it's raising its importance a little bit.

Moderator: Mhm, I agree. When you do have people responding to your social media, you said that Twitter for example was something you had a larger audience for. Do you get a lot of interactions with them and if so, what kind of interactions do you receive?

Schindelar: Um, we definitely get a lot of, um, comments on our Facebook pages. We don't see as much interaction on our Twitter profiles as we do on our Facebook. I think maybe just because it's more public that it's on Facebook and it's actually on our page. $\mathrm{Um}$, we have some topics that are very controversial, so I think that anytime around vaccines or um, lime disease, actually raw milk was a very heated debate that went on our Facebook page. So there are some topic areas that definitely get a lot of comments back and forth. We see a lot more people posting questions on our Facebook wall, which we'll then send back to the programs to respond to. But then we also do some kind live Twitter chats, and sometimes Q\&A sessions on Facebook where we give 
followers an opportunity to answer questions in real-time and those seem to be, um we get a lot of traffic on those.

Moderator: That's interesting. I like that. Well, I think my only other questions as a follow up is, with the blogs, in my research I found a lot about blogs in particular. Do you think that have been influential at all, or do you think that's not something to be concentrating on?

Schindelar: I think blogs are definitely, I mean they're not going anywhere. I think they've become much more popular especially from the news perspective. I mean, I know just from how popular Huffington Post is they think that's it a real news outlet and it really is a blog.

Moderator: That's true. It seems like the CDC blogs are catered toward the health professional. Do you find that some of them are getting some interaction with the general public?

Schindelar: Um, yeah I mean I think that they're definitely catered to a whole host of different audiences. I think people don't realize they're reading blogs sometimes. But they definitely are.

Moderator: And the authors of those blogs, are they generally professionals?

Schindelar: Yes, a lot of them are actually at the senior leadership level at the CDC. So division director and center directors, so it's kind of a higher level. Most of them are higher-level staff in the CDC.

Moderator: Okay, and it's generally not a communications staff member?

Schindelar: Um, it's probably the communications people who are writing a lot of it. It's kind of a team effort where the senior leadership may be on the title of the blog, but it has been co-written by. I mean they are definitely in the last line of approval of whether or not their name is associated with it. But there's probably a lot of ghost writing going on where the communications staff are writing the post and then getting the sign off of the leadership to post under their name.

Moderator: Well, that is all I have for you and I really appreciate you answering all these questions about your job.

Schindelar: You're very welcome.

Moderator: And if you happen to redact your name later, you can always call me or email me at any time and I can do that for you. Otherwise, any other questions you can also email me or call me. But that is about it for the interview. Would you like me to send you the results of the study at the end? 
Schindelar: Yea, that would be great. l'd love to see those.

Moderator: Okay, I will do that. Thank you very much.

Schindelar: You're welcome.

Margaret (Maggie) Silver

November 16, 2011 at 11:30 a.m., ended at 11:54 a.m.

Silver: In terms of the zombie campaign, I'm involved in everything. As far as the CDC as a whole goes, I can give you some basic information about the CDC's involvement with mainstream media. And then I'm also a part of the social media counsel here at the CDC, so I can give some pretty detailed answers to CDC's involvement in social media.

Moderator: Okay, well how long have you been employed at the CDC?

Silver: Uh, about a year and a half with the CDC. Prior to that, I was with a different federal agency.

Moderator: Okay. I talked to somebody else and they said they had different communications teams for different departments and institutions, so are...

Silver: Okay, sure. Sorry, the CDC, I don't know if you're aware of the CDC's organization. But basically we're set up into different centers, offices, and institutes. So, um, for each different health area there's going to be a different COI (Center, Office, Institute). So, for example, I work for the Office of Public Health Preparedness and Response. So, um, emergencies, natural disasters, food outbreaks, or HINI, stuff like that. That's what our office deals with and we've got communicators within our office. And then something like the AIDS group, they've got their own set of communicators. And then there's this overarching umbrella, the Office of the Director, they've got their own communicators there and they kind of oversee everything within each $\mathrm{COI}$, and each $\mathrm{COI}$ has their own collection of communicators.

Moderator: Okay, and so for you, what is your main job function there?

Silver: So, I do media relations, I do social media, I do internal communications, so um we've got a couple newsletter type items that I help with. Um yeah, I do events, like event planning, and then I also do staffing for our director and our senior leaders so that includes, developing talking points for them when they go to conferences, or when they go and speak to the media or partner organizations. Um, so it's really a wide range. If we do a campaign, I also have a role in that developing health messages and the campaign and doing research.

Moderator: That sounds like a lot of fun.

Silver: Yeah, so um, it varies a lot. Some communicators in different areas at the CDC have a more focused role, but that happens to be my role. 
Moderator: Right, yeah. Well you did mention that you work with the media a little bit with media relations, so what do you consider your main form of communication with the media, when you're trying to send out your campaigns or disseminate messages to them?

Silver: Um, well, our office does a really good job with maintaining relationships with media contacts.

Moderator: Mhm.

Silver: And we have a couple of mainstream media contacts, like say at the Wall Street Journal, at CNN, NBC, New York Times, in different areas. Then we also have the Atlanta-based journalists that we'll meet with periodically. We try to maintain that relationship, whether it's just a friendly e-mail with a heads up that we've got a project coming down the pipe, just meet them for coffee. You know, we try to maintain a certain level of relationship so when we do have something coming they trust us, we trust them, and we give the highlights of our story in turn hope that they run it.

Moderator: Okay, and um, when you do have your campaign and your messaging, do you find that the media often pick up more so the press releases and media advisories or do they respond more to those e-mail release, the blogs, or the Vital Signs and all that stuff?

Silver: Um, you know, we've noticed that it's more if we put stuff out there, they'll pick it up. So we have our blog and we'll do blog stuff a lot and people will pick it up. But, for example, if we write a new blog post, it's not just post it to the web site. We then tweet about it and we post it on Facebook, if it's something really interesting we'll shoot an email to one of our media contacts. Um, and it'll get picked up that way.

Moderator: Okay.

Silver: I think, you know, it's not just having it on the web site, people aren't necessarily coming to that. They're seeing it getting retweeted, or um we send a direct message to them.

Moderator: Okay, do you guys have your own strategic communications plan, separate from the overall CDC communications plan?

Silver: Yeah, if we got a project coming up, we'll kind of do our own marketing plan for it. And that involves all forms of communications, so both social media, plain webbased, and also our mainstream media contacts. And because there are different levels of CDC, we'll post stuff on our own channels and then we'll also send stuff up to the OD, the Office of Director level. So, you know, CDC has their own Twitter and Facebook page, but then our office also has our own channels that we use, like CDC Ready and 
CDC Emergency Facebook page. But then we'll also send it out at @CDCgov and the main CDC Facebook page. If that makes any sense.

Moderator: It does!

Silver: Okay.

Moderator: And so, with this communications for a certain campaign for example, do you guys have a list of key messages that you want to be disseminated? How do you choose issues for each campaign, how does that come about?

Silver: Well we'll create talking points or issues, and anytime anyone's going to be a spokesperson for us, we'll make sure they have a copy of that. So if our offices director, Dr. Ali Khan, goes out to speak to a group, he's got a list of those talking points and they'll include our key messages in our marketing plan that I just mentioned, we'll make sure we've got those listed out. And we'll develop tweets or Facebook posts around those key messages.

Moderator: Okay. Back to traditional media, such as the press release or media advisory, do you work with those traditional tactics as well?

Silver: Can you say that a little bit louder?

Moderator: Yeah, do you work closely with the traditional tactics as well, such as the press release, media advisory, in the media newsroom? Is that something you work with as well?

Silver: You know, we don't do press releases as often as you might think. CDC as a whole might do it for the Syria outbreak, they had a press release and they also had a press briefing and they had Dr. Frieden and someone from USCA, they held a formal press conference. But you know, sometimes we'll put on the CDC main page there's an "In the News" section, and we'll develop something for that. But for the most part, it's our office and we'll identify what our key messages are and again, we send them out kind of in our own channels. But, I say because we've got a good relationship with a lot of...

Moderator: Media members?

Silver: Yeah, media members. We don't necessarily need to do that formal.

Moderator: Yeah, that's interesting though, that's good. And so for social media, I'm assuming that you guys have also a set of key messages to disseminate through your social media outlets as well. And the same topics being disseminated through that and mainstream? 
Silver: Yeah, we're trying to be consistent with our messaging, so whatever Dr. Khan is saying we're making sure that's coming out as well as through Twitter, and Facebook, and a blog post or whatever we're doing.

Moderator: Okay, so obviously the traditional stuff like the press release or your contact with the media is catering toward media people. But, for your social media, what audience do you think your social media content caters toward?

Silver: Um, so for every CDC's Office or Center that creates a Twitter or Facebook page, they have to come up with a social media plan, and that includes what the audience is. So ours is public health practitioners, people in emergency response, you know people associated with like that firefighters, EMS, things like that. The general public, but then we also have listed media as one of our target audiences.

Moderator: Okay, for your social media content specifically?

Silver: Mhm. Because they really do use it to get information. For example, with the zombie campaign, we did a soft launch on Monday, we got a little bit of buzz about it. But it wasn't until we tweeted about it on Wednesday that we just got this flood of calls and our server crashed 10 minutes after our first tweet. And so it was like, even though we just posted it online on Monday, it wasn't getting that much buzz until Wednesday morning FOX News, one of the first people to call because they'd seen this tweet and they weren't sure if we'd been hacked or not.

Silver: So, you know, we do find social media useful for connecting to the media.

Moderator: Okay, so that's interesting. It sounds like your using your blog as the outlet for the messages, but people are grabbing it from the social networking sites.

Silver: Right, exactly. So that's what I was alluding to before when I was saying, you know, we might post stuff on the blog, but we use social media to promote that content.

Moderator: Okay.

Silver: And that's really how we drive a lot of traffic to the site. I was talking to a group before, and some people were like, "Oh, we're really not into social media, you know, most of our stuff is just web-based." And I explained to them a lot of our stuff is webbased too, we have a lot of content, we have too much to put on social media. But we use social media to drive people to that content.

Moderator: Right, the important things that you want them to go to.

Silver: Exactly, yeah.

Moderator: Okay. Now this is kind of related to social media, the social media release Vital Signs, I find that very interesting about how you guys are using that. Do you 
particularly have any involvement with that, or does your office have any topics that go in it a certain month?

Silver: For the Vital Signs? No, we don't.

Moderator: Okay, I know the topics are set every month, so I didn't know if anything correlated to your office or not.

Silver: Yeah, no. Unfortunately, I want to say Vital Signs is only winnable battles, which are different topics that our Director has identified as things that we should be able to make progress in over the course of a certain amount time. So they usually focus Vital Signs on those winnable battles and emergency preparedness is not chosen as a winnable battle.

Moderator: Okay, are you saying winnable...

Silver: If you want to know more about that, I can find the right person to talk to you.

Moderator: Okay, yeah! Because for my study, talking to you and some other people at the CDC, I'm kind of identifying what tactics you guys think have been most influential in gaining a presence with the media and with an overall audience. It sounds like so far Twitter and Facebook have been the main one. But Vital Signs, I find interesting as well, so I might want to hear more about that too.

Silver: Sure, so I just wrote down a note about that and l'll try to pin down the best person for you to talk to and get linked up with them.

Moderator: Okay, thank you. A few more questions. So, for your social media specifically, do separate people write the Facebook and the Twitter content, how does that work for you?

Silver: Um, again that kind of depends on the center or office that you're in. Social media is actually a lot of work.

Moderator: Yes!

Silver: Yeah, we have, I mean it's a full time job just trying to manage that. I personally help with the, two of our Twitter accounts, which are @CDCReady and our director's account, @CDCDrKhan. And some different communicators work on the CDC Emergency Facebook page. So for our office, it's separate a little bit. For other offices it might be the same team working on all of the messages. For CDC policy, we've got what some would say is a strict social media policy, others may say it's not. But we have to have all of our messages cleared through our Associate Director of Communication. So, even if different people are coming up with the messages, they're supposed to be cleared through one person to make sure, before we send it out, that it's properly representing the agency. 
Moderator: Right. How far in advance do you generally have to get those approvals sent?

Silver: This is the recommendation from the social media council here at CDC for doing stuff like that. You should always have some pre-cleared tweets of FB messages. So for example, in emergency preparedness, we have pre-cleared tweets on a lot of different natural disasters. Because we know they will inevitably happen at some point. Or certain times of the year, when it's emergency preparedness month, we'll have precleared tweets and we can just send those out and we don't have to worry about them. In terms of ones we make up on the fly, our ADC (Associate Director of Communications) is very laid back and very trusting of us.

Moderator: That's good.

Silver: Because he doesn't feel like he needs to double-check everything, whereas other centers it may take a little bit long. So it could be five minutes or it could be a day depending on your director.

Moderator: Okay. For measurement, I have a few questions about that. How do you measure or seek to evaluate what seems to be most effective in media coverage? Do you use any measurement tools, do you evaluate yourself, how does that work?

Silver: Sure. There are a couple things, for the zombie campaign that recently happened, the CDC already had a standing contract with a group called Cision. And they monitor media coverage, both online, social media, and mainstream media. They were able to track the first 2 weeks after our blog went out. And we got a lot of our stats from them, kind of our marketing saturation that our campaign got. CDC also just started a contract with something called Radian 6 . That will track the organic growth of a campaign. You have to know beforehand that you're going to do that. But for example, the CDC has a campaign going on called Million Hearts, that's through the chronic center. So they're using Radian 6 to track the growth of that campaign to see how many times it's being mentioned through social media outlets, what articles are being written through it. So different centers and offices will use different tools, Radian 6 and Cision are things that we're doing right now. For tracking web metrics, we use Adobe's Omniture. We'll also just do our own environmental scans.

Moderator: Okay, yeah.

Silver: Okay, you know what that is. Okay, it just kind of depends what you have set up beforehand, but the CDC does have contracts with different groups. So if you're planning something big, you can start tracking it from the beginning.

Moderator: Right. And so with your experience personally, have you found that a certain tactic is most effective in reaching media outlets, as opposed to other ones? Using these measurement tools? 
Silver: Um, we haven't personally got to use Radian 6 yet, so I can't speak to that. Having Cision was very helpful, because we never would have been able to track the content that they gave us. I would highly suggest that if someone is going to do a large campaign that they find something to track the mainstream media coverage, because it's very hard to do it with your own environmental scans. So having something set up, I think it's helpful if you want to get good stats on what your campaign is doing. I don't know if that really was a great answer.

Moderator: No, you're fine. So let me see... For you, are you active in blogging, do you read blogs, are you active in social networking yourself?

Silver: Yeah, on a personal level, yes. For my work, that's my job, I manage the social media accounts.

Moderator: Yeah.

Silver: But outside of work, I definitely try to stay on top of it. I've probably gotten more into because of my work. I start understanding the importance of it. I catch myself telling my friends that you really should get on Twitter, solely for staying up to date on what's happening in the world. That's what I use my Twitter account for, tracking media and what comes up in the media. And I notice I do that now more because of my job in my personal life. I look at blogs more and I value the importance of those outlets.

Moderator: Okay. And this is a hard question; the other person I interviewed was kind of stumped too. But, how do you see social media (blogging, social networking sites, all that stuff) influencing the nation's health agenda and their audiences, if at all?

Silver: Um, well I definitely think that it can influence and it can be a positive influence. I think it allows agencies like CDC to get into the conversation by using social media and different outlets like that. For example, there are a lot of people out there that think vaccines cause autism. There's a lot of people blogging about it, there's a lot of people with Facebook pages, or commenting on Twitter about it. And having these things allows us to get into the conversation and direct people to resources from a reliable source that explains what the risks are with these different vaccines or other health related topics. So I think that whether it's social media, or blogging, or web content, I think it's very important for public health and health practitioners to get into the mix because it's a tool that we can use to reach a larger audience and help direct to reliable information, and information that we want them to get and understand.

Moderator: Okay.

Silver: I got kind of lost in that. 
Moderator: No, that made perfect sense actually. Last question, do you find individuals or the media interacting with or responding to social media tactics? And why do you think that is?

Silver: Um, I definitely think that media is responding to our tactics, because we will get media contacting us because they saw something on social media.

Moderator: And the zombie campaign is a perfect example of that.

Silver: Right, exactly. And I can send you a very short paper that we wrote up after the initial blog post went out, just about metrics and why we think it worked and a timeline of the campaign. If that would help you at all.

Moderator: Yeah, that would be great. I found this very interesting and very helpful for my thesis. I really appreciate you talking to me.

Silver: Yeah, sure, no problem Kristen.

Moderator: And do you have any other questions for me about this?

Silver: No, I think we're fine. We're actually talking to a lot of students who've been calling about this. Which I think is great. I don't know if you're getting your MPH or what degree you're getting.

Moderator: Masters of Science in Journalism, actually.

Silver: Oh okay. Well I have an MPH and they never really talk about this kind of outreach in school and I think it would have been helpful.

Moderator: It's definitely picking up. And if later you decide later, hey I really don't want my name in the thesis; you can redact your name. It won't be included. You can email me at any time and say that you want to do that. And, that's about it.

Silver: Okay, excellent. And I'll send a couple people an email who you can talk to about Vital Signs. And l'll send you that zombie paper.

Moderator: Okay, sounds great. Thank you so much. 
Appendix D: Coding Sheets \& Instructions

Twitter Coding Sheet

Coder Initials

\begin{tabular}{|l|l|}
\hline & \\
\hline
\end{tabular}

MM/DD/YY

\begin{tabular}{|l|l|l|l|l|l|}
\hline & & & & 1 & 1 \\
\hline
\end{tabular}

Medium: CDC tweet (@CDCgov) - 1

\section{Content}

What is the main topic(s) of the piece? (Refer to the coding instructions for definitions)

Are hashtags and/or links provided in the tweet?

$$
\text { Yes }-1
$$

No -2

Please include hashtags and/or URL(s):

Comments/Notes: 


\section{Twitter Coding Instructions}

Fill out one form per @CDCgov tweet.You will find definitions and examples below to help you select the appropriate category.

While coding, please list the number that corresponds to the tweet in the top, right-hand corner of the coding sheet.

\section{Coder}

Initials of coder.

\section{MM/DD/YY of the Tweet}

Enter the information in a two-digit format. For example, if you were coding a tweet sent on September 1, you would enter 0901. Because all of the mediums in this sample are from the year 2011, "11" has already been listed in the year box.

\section{Medium}

Check $(\checkmark)$ beside the medium on the code sheet that corresponds to the type that you are coding, even if it is obvious.

\section{Content}

\section{First:}

Remember, this study is interested in what health topics are being discussed throughout CDC media. Health topics include subjects such as diabetes prevention, cancer, tobacco use, childhood obesity prevalence, teenage pregnancy, etc. Words such as prevention, prevalence, decrease/increase, safety, etc. should only be included in the main topic(s) section if it would change the meaning of the topic in the piece without that word.

\section{Second:}

To determine the health topic(s), refer to the tweet to determine the main topic. Some tweets may seem confusing because they are part of a conversation or promoting an unfamiliar event. Don't forget that these tweets were in a timeline of a conversation, and we have only taken a sample of this conversation. If you find yourself questioning the main topic of the tweet, please make your best guess as to the main health topic of the tweet. If there is no health topic, please list the main purpose of the tweet.

\section{Hashtags}

Hashtags refer to the \# symbol used to mark keywords or topics in a tweet. There may be multiple hashtags in one tweet. 
If there is a hashtag provided in a tweet, please check (प) "Yes" on the coding sheet. Please list the given hashtag in the space below.

If there are no hashtags or links, please check "No" on the coding sheet.

\section{Comments/Notes}

Please note any peculiarities of a tweet, if it mentions someone within the tweet (Such and such message with @twitterhandle), or if you had a particularly hard time understanding the tweet and why. 


\section{CDC Coding Sheet}

Coder Initials \begin{tabular}{|l|l|}
\hline & \\
\hline
\end{tabular}

\begin{tabular}{|l|l|l|l|l|l|}
\hline MM/DD/YY & & & & 1 & 1 \\
\hline
\end{tabular}

CDC Medium:

CDC Vital Signs issue -2

CDC Press release -3

CDC Media advisory - 4

Headline (copy verbatim):

\section{Content}

What is the main topic(s) of the piece? (Refer to the coding instructions and codebook for definitions)

Comments/Notes: 


\section{CDC Coding Instructions}

Fill out one form per CDC piece or AP story. You will find definitions and examples below to help you select the appropriate category.

\section{Coder}

Initials of coder.

\section{MM/DD/YY of the Medium}

Enter the information in a two-digit format. For example, if you were coding a press release that ran on September 1, you would enter 0901. Because all of the mediums in this sample are from the year 2011, "11" has already been listed in the year box.

\section{Medium}

Check $(\checkmark)$ beside the medium on the code sheet that corresponds to the one you are coding.

\section{Headline}

Enter the headline of the piece verbatim. Press releases may have a subhead under the headline. Do not list subheads in this space, but you may refer to them to determine the main topic(s) of the piece. If there is no headline given, please write $\mathrm{N} / \mathrm{A}$.

\section{Content}

\section{First:}

To assess the health topic of the piece, first remember that this study is only looking at the general health topic, not the frame, audience, or other details. General health topics include subjects such as diabetes prevention, cancer, tobacco use, childhood obesity prevalence, teenage pregnancy, etc. Words such as prevention, prevalence, decrease/increase, safety, etc. should only be included in the main topic(s) section if it would change the meaning of the topic in the piece without that word.

\section{Second:}

To determine the health topic(s), refer to the headline and lead paragraph of the piece. If it is difficult to determine the main topic, please continue to read another paragraph until you can determine the topic. If it is apparent that there is more than one main health topic, please include both. 
For example, if you read a press release about salmonella but the data are from a Vital Signs release, please include that in your coding. Another example is a press release or media advisory on a fundraising or awareness campaign, but the health topic is cardiovascular health, include both the campaign name and the health topic. Please use your best judgment on determining the main health topic(s).

\section{Media advisories:}

If an event is being promoted, please list the event specifically and the topic(s) and/or person(s) that it surrounds. Do not worry about the time, place, or other specifics that don't influence the content of the topic. People are often mentioned in media advisories, but if they are not significant in the health topic, do not include them in your analysis. 


\section{AP Coding Sheet}

Coder Initials

\begin{tabular}{|l|l|}
\hline & \\
\hline
\end{tabular}

MM/DD/YY

\begin{tabular}{|l|l|l|l|l|l|}
\hline & & & & 1 & 1 \\
\hline
\end{tabular}

AP Story:

AP story -5

Headline (copy verbatim):

\section{Content}

What is the main topic(s) of the piece? (Refer to the coding instructions for definitions) 


\section{AP Coding Instructions}

Fill out one form per AP story. You will find definitions and examples below to help you select the appropriate category.

\section{Coder}

Initials of coder.

\section{MM/DD/YY of the Medium}

Enter the information in a two-digit format. For example, if you were coding an AP story that ran on September 1, you would enter 0901. Because all of the mediums in this sample are from the year 2011, "11" has already been listed in the year box.

\section{Medium}

Check $(\checkmark)$ beside the medium on the code sheet that corresponds to the one you are coding.

\section{Headline}

Enter the headline of the piece verbatim. If there is no headline given, please write $\mathrm{N} / \mathrm{A}$.

\section{Content}

To assess the health topic of the piece, first remember that this study is only looking at the general health topic, not the frame, audience, or other details. To guide you, 14 health categories have been listed and defined for you to properly select the health topic of each story.

Please read through each category carefully, as each category lists more specific definitions of what may be included within that category.

The code numbers listed below do correspond to each health category. For example, the category of "Environmental Health" should be coded as "1". 
Appendix E: Codebook

(Using Non-Collapsed Health Topic Categories)

\begin{tabular}{|c|c|c|}
\hline Variable name & Variable categories & $\begin{array}{c}\text { Variable } \\
\text { codes }\end{array}$ \\
\hline Date (MM/DD/YY) & Medium date & $\begin{array}{c}02 / 01 / 11- \\
07 / 31 / 11\end{array}$ \\
\hline \multirow[t]{6}{*}{ Medium } & CDC Tweet & 1 \\
\hline & CDC Vital Signs release & 2 \\
\hline & CDC Press release & 3 \\
\hline & CDC Media advisory & 4 \\
\hline & AP Story & 5 \\
\hline & Not available (N/A) & 12 \\
\hline \multirow[t]{3}{*}{$\begin{array}{l}\text { Health Topic } \\
\text { Environmental health }\end{array}$} & Recycling, environment, etc. & 1 \\
\hline & $\begin{array}{l}\text { Animal handling \& outdoor disease or } \\
\text { infections }\end{array}$ & 2 \\
\hline & $\begin{array}{l}\text { Water safety and health, healthy } \\
\text { swimming contest }\end{array}$ & 3 \\
\hline Toxic substances/contaminants & ATSDR & 4 \\
\hline \multirow[t]{4}{*}{ Injury prevention } & $\begin{array}{l}\text { Falls, poisoning, risk behavior, suicide, } \\
\text { TBI's, extreme weather illness }\end{array}$ & 5 \\
\hline & Motor vehicle injury & 6 \\
\hline & Violence, abuse, maltreatment & 7 \\
\hline & Elder population abuse/disparities & 8 \\
\hline
\end{tabular}




\begin{tabular}{|c|c|c|}
\hline International travel & & 9 \\
\hline Teen pregnancy & Birth rates, prevention & 10 \\
\hline \multirow[t]{3}{*}{ Chronic diseases } & Cancer (mostly colorectal) & 11 \\
\hline & Arthritis & 12 \\
\hline & Other & 13 \\
\hline Asthma & Attacks, triggers, prevention, plans & 14 \\
\hline Family health & General teen, child, parenting & 15 \\
\hline CDC Twitter promo & $\begin{array}{l}\text { Surveys, contest, twitter communication, } \\
\text { video/social media promo }\end{array}$ & 16 \\
\hline National health data & $\begin{array}{l}\text { Health report, research, no health topic } \\
\text { listed }\end{array}$ & 17 \\
\hline Women's health & $\begin{array}{c}\text { General pregnancy tips and women's } \\
\text { health }\end{array}$ & 18 \\
\hline STD's & HIV/AIDs, testing \& screenings, sex & 19 \\
\hline \multirow[t]{2}{*}{ Blood disorders } & Sickle cell disease & 20 \\
\hline & $\begin{array}{l}\text { Other (blood clots, hemophilia, } \\
\text { thalassemia) }\end{array}$ & 21 \\
\hline \multirow[t]{4}{*}{$\begin{array}{r}\text { Birth defects \& developmental } \\
\text { disabilities }\end{array}$} & NCBDDD, pregnancy & 22 \\
\hline & Autism & 23 \\
\hline & Cerebral palsy & 24 \\
\hline & Hearing loss & 25 \\
\hline
\end{tabular}




\begin{tabular}{|c|c|c|}
\hline & Spina bifida & 26 \\
\hline & Birth defects (general topics) & 27 \\
\hline Eye health & Exams, illness & 28 \\
\hline $\begin{array}{r}\text { Food safety and foodborne } \\
\text { illness }\end{array}$ & Food safety, handling, germs, salmonella & 29 \\
\hline $\begin{array}{r}\text { Healthcare-associated } \\
\text { infections }\end{array}$ & $\begin{array}{c}\text { Central-line bloodstream infection, MRSA, } \\
\text { surgical }\end{array}$ & 30 \\
\hline Obesity & $\begin{array}{c}\text { Rates, prevalence, physical inactivity, } \\
\text { risks }\end{array}$ & 31 \\
\hline Food health & $\begin{array}{l}\text { Childhood/teenage healthy eating, sugary } \\
\text { drinks, sodium intake, potassium intake }\end{array}$ & 32 \\
\hline Public health & $\begin{array}{c}\text { Public health advances, services, } \\
\text { agencies, global health, Public Health } \\
\text { Informatics }\end{array}$ & 33 \\
\hline & $\begin{array}{l}\text { CDC Grand Rounds (public health } \\
\text { webcast on specific topics) }\end{array}$ & 34 \\
\hline Tobacco & Cessation, smoke-free laws, control & 35 \\
\hline Emergency preparedness & $\begin{array}{l}\text { Radiation emergencies, natural disasters, } \\
\text { emergency responders, extreme heat }\end{array}$ & 36 \\
\hline Antimicrobial resistance & $\begin{array}{l}\text { Antibiotics, World Health Day, drug- } \\
\text { resistance, }\end{array}$ & 37 \\
\hline Immunization/vaccines & $\begin{array}{l}\text { Polio, rabies, measles, tetanus, etc. for } \\
\text { infants, children, teens, adults, etc. }\end{array}$ & 38 \\
\hline Disabilities & $\begin{array}{c}\text { Data by state, Tourette's, muscular } \\
\text { dystrophy }\end{array}$ & 39 \\
\hline \multirow[t]{3}{*}{ Disease } & ALS & 40 \\
\hline & Measles & 41 \\
\hline & Hepatitis & 42 \\
\hline
\end{tabular}




\begin{tabular}{|c|c|c|}
\hline & Tuberculosis & 43 \\
\hline & Diabetes & 44 \\
\hline & $\begin{array}{l}\text { Heart health/disease (i.e. high blood } \\
\text { pressure/cholesterol, heart disease, } \\
\text { stroke) }\end{array}$ & 45 \\
\hline & $\begin{array}{l}\text { Other (meningitis, dengue, Scarlett fever, } \\
\text { misc.) }\end{array}$ & 46 \\
\hline Other & Do not fit in any of the above categories & 47 \\
\hline Hashtag & Yes & 1 \\
\hline \multirow[t]{2}{*}{ Emerging in tweets only } & No & 2 \\
\hline & $N / A$ & 12 \\
\hline
\end{tabular}




\section{Appendix F: CDC Organizational Chart}

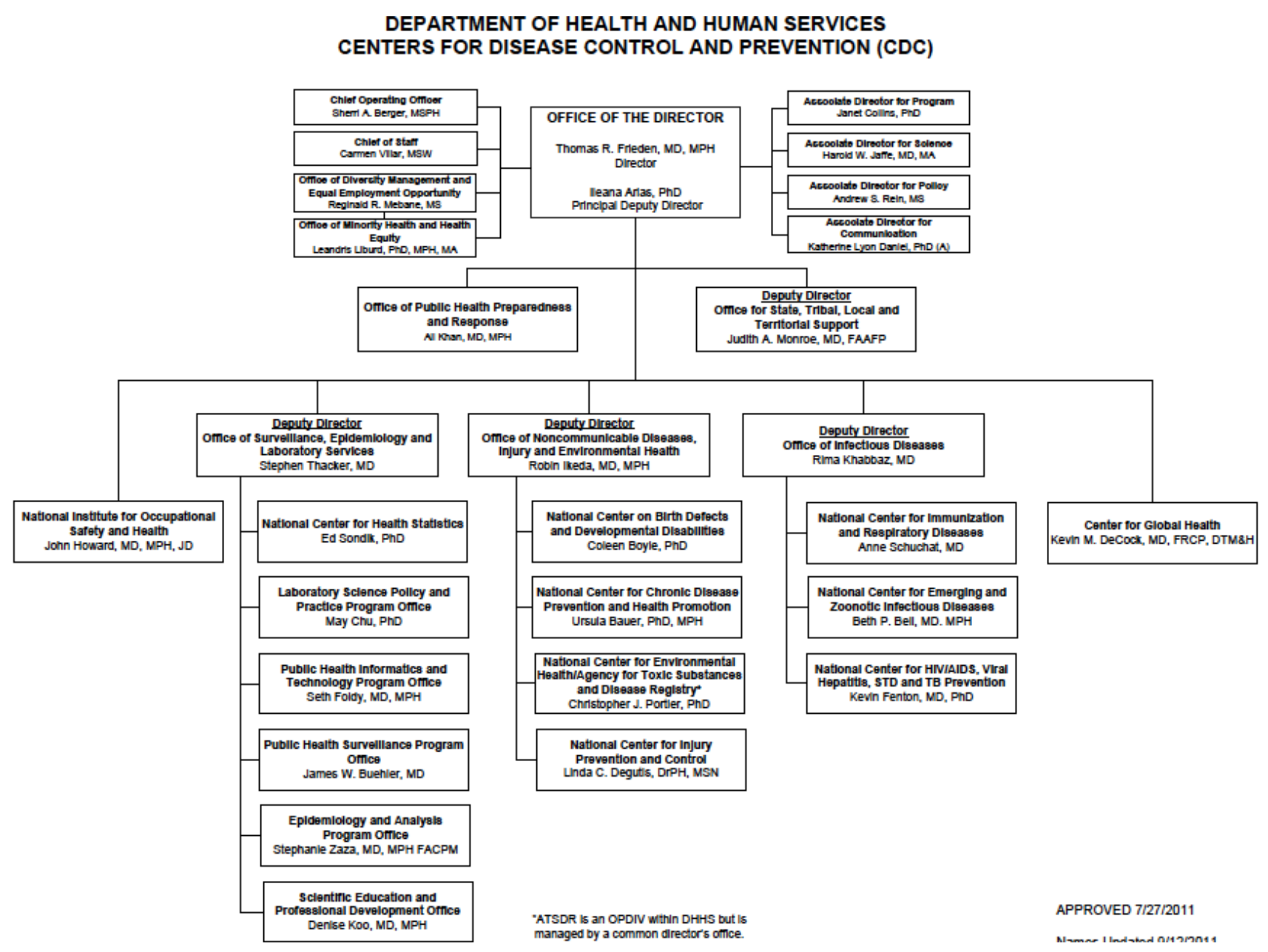

